\title{
The Theory of the Revenue Maximizing Firm
}

\author{
Beniamino Moro \\ Department of Economics, University of Cagliari, Viale Sant'Ignazio 17 - 09123 Cagliari (Italy) \\ Email: moro@unica.it
}

\begin{abstract}
An endogenous growth model of the revenue maximizing firm is here presented. It is demonstrated that, in a static analysis, a revenue maximizing firm in equilibrium equates the average product of labor to the wage rate. In a dynamic analysis, the maximization rule becomes the balance between the rate of marginal substitution - between labor and capital - and the ratio of the wage rate over the discount rate. When the firm satisfies this rule, it grows endogenously at the rate of return on capital. The firm may also have multiple stationary equilibria, which are very similar to the static equilibrium.
\end{abstract}

JEL classification: D21, O41.

Keywords: firm, theory of the firm, revenue maximization, endogenous growth

\section{Revenue Maximization Versus Profit Maximization and the Theory of the Firm}

The original idea of a firm that maximizes revenue instead of profit was put forward by Baumol [2, 3], and further investigated during the sixties by Cyert-March [12], Galbraith [19], Winter [39] and Williamson [36]. Autonomously, a similar idea was also investigated by Rothbard [31], a precursor of the Austrian theory of the firm. ${ }^{1}$ Nonetheless, the main stream economic thought, as Cyert-Hedrick [11] pointed out in their review article, remains characterized by an ideal market with firms for which profit maximization is the single determinant of behavior. ${ }^{2}$ Indeed, the relevance of pure profitmaximization is not so obvious for modern corporations when ownership and control of the firm are separated and there are no dominant owners that merely maximize their profits [27].

\footnotetext{
${ }^{1}$ See Anderson [1], and for the Austrian school see Foss [15, 18], and Witt [41]

${ }^{2}$ In fact, during the " 30 s and ' 40 s, a great dispute was due to the "Old Marginalist Debate" which questioned the relevance of the profitmaximization assumption in neoclassical theory of the firm. In the " $70 \mathrm{~s}$, the marginalist debate changed tone with the emergence of the theories of agency costs, property rights, and transactions costs theories of the firm. These gave rise to the "New Institutionalist" field of research, where the object of study changed from how to reconcile firm behavior with marginalist principles to how to reconcile firm structure with marginalist principles. Following the seminal work by Coase [8], papers belonging to the Institutionalist debate can be divided in the transactions costs economics $[24,37,38]$, and the contractual field of research $[6,13$, $21,22]$. The old marginalist debate re-emerged in the ' $80 \mathrm{~s}$ with the evolutionary theory of the firm by Nelson-Winter [30], Winter [40], and Foss [14]. Finally and more recently, we also have a "Knowledgebased" theory of the firm $[16,17,20]$, and a "Resource-based" theory [9, $10]$.
}

More recently, the revenue-maximization dominance hypothesis has been re-proposed by Uekusa-Caves [34], Komiya [25, 26], Blinder [4, 5] and Tabeta-Wang [32, 33]. In all these papers it is argued that the separation of ownership and control in public companies causes a deviation of management from the pure profit maximization principle and provides a considerable degree of decisionmaking autonomy for managers. In fact, in an oligopolistic market, each firm may set up its own goal, and the choice to maximize revenue or profit depends on the real interests of the managers, and is also influenced by the corporate culture and institutional arrangements of the country where the firm operates. According to Kagono et al. [23], the principal objectives of Japanese firms are growth and market-share gaining, which imply that they are revenue maximizers, while US corporations emphasize more on short run investment returns and capital gains, which means that they are profit maximizers. ${ }^{3}$ In

\footnotetext{
${ }^{3}$ Blinder [5] builds up a model to demonstrate that revenue-maximizers like Japanese firms have an advantage when competing with profitmaximizers. Particularly, he points out that the revenue-maximizer is likely to drive its profit-maximizers rivals out of business if either average costs are declining or learning is a positive function of cumulative output. Tabeta-Wang [33] find the following four reasons to explain why Japanese firms are in general able to act like revenue-maximizers. First of all, in Japan, expansion in firm-size is a necessary condition to maintain the life-time employment system and internal promotion. Secondly, a faster growth of the firm helps hiring new young employees, and keeping low the average age of the work force helps to maintain low labor costs. Thirdly, Japanese firms pursue the growth-oriented strategy also because there is little external pressure for short-term earnings, and tax rates on reinvested earnings are lower than tax rates on dividends.
} 
fact, as Anderson [1] points out, the profit maximizing versus the revenue maximizing strategy of the firm still stays as an open question, the answer to which only time will tell.

A parallel problem to this dispute is how to formalize the firm behavior in the two cases. At this regard, the mainstream microeconomic analysis has been mainly oriented to the profit maximization strategy, while very little attention has been devoted to the revenue maximizing case. Apart from the static analysis during the sixties, the latter field of research is very poor. After the seminal work by Leland [28], Van Hilton-Kort-Van Loon [35] and Chiang [7] put the problem in the contest of the optimal control theory and demonstrated that a revenue maximizing firm subject to a minimum profitability constraint is in equilibrium at a smaller capital-labor ratio than a profit maximizing one. This result is also obtained here. Anyway, Leland's model suffers of some limitations - e.g. he considers constant the share of profits used to self-financing the accumulation of capital - which preclude him to develop a complete dynamic model which fully describes the dynamics of a revenue maximizing firm. The aim of this paper is to fill the gap in this field of research, presenting a complete endogenous growth model of a revenue maximizing firm.

The paper is organized as follows. In section 2, the problem of a revenue maximizing firm versus the classical problem of profit maximization is analyzed from a static point of view. First of all, the analysis is made without taking into account a minimum acceptable return on capital constraint (section 2.1) and then with such a constraint (section 2.2). In section 2.3, the analysis is generalized into a rate of profit maximization problem and into a revenue per unit of capital maximization problem, respectively. We obtain the fundamental rule followed by a static revenue maximizing firm, according to which the firm equates the average product of labor to the wage rate. The same rule also applies in a dynamic context.

In section 3 , we use the optimal control theory to describe the dynamics of a revenue maximizing firm. With respect to Leland's model, this paper differs on the following two assumptions: a) we suppose that the firm's accumulation of capital is limited to the non distributed profits and b) we also suppose that the share of the reinvested profits is endogenously determined by the firm, while in Leland's model this is a constant. We also demonstrate that only some of the possible dynamic equilibria (stationary equilibria) correspond to those discussed in the static analysis. Anyway, it is also demonstrated that an endogenous growth equilibrium of the firm does exist,

Lastly, there is some possibility that administrative guidance and controls lead Japanese firms to act like revenue-maximizers. At this regard, Nakamura [29] clamed that administrative guidance and controls play a role as a "shelter from the storm" once the firm grows beyond the limits of a market accepted profitability. where the rate of growth is obtained from the solution of a system of differential equations which fully describes the dynamics of the model. Also in this section, the problem is first analyzed without taking into account any minimum acceptable return on capital constraint (sections 3.1-3.4) and then with such a constraint (section 3.5). Our main conclusion is that, in a dynamic context, the equilibrium of a revenue maximizing firm requires not only that the marginal rate of substitution between labor and capital to be equal to the shadow value of the capital-labor ratio, but that this value also balances the ratio of the wage rate over the discount rate.

Further, if we introduce a minimum acceptable return on capital constraint, this must be added to the discount rate when determining the equilibrium equality with the rate of marginal substitution between labor and capital. As a consequence, a change of the minimum acceptable return on capital rate has the same effect as a variation of the discount rate. Finally, section 4 is devoted to the concluding remarks.

\section{The Static Analysis of the Firm Behavior}

\subsection{The Equilibrium Conditions Without a Minimum Acceptable Return on Capital Con- straint}

We make the following neoclassical assumptions on the firm production function $Q=Q(K, L)$, where $K$ is capital and $L$ is labor:

a) $Q$ is linear homogenous and strictly quasi-concave, which implies that $Q=Q(K, L)=L f(k)$, where $f(k)=Q(K / L$, 1) and $k=K / L ; f(0)=0$ and $\lim _{k \rightarrow \infty} f(k)=\infty$;

b) the marginal productivity of capital $Q_{K}=f^{\prime}(k)$ has $\lim _{k \rightarrow 0} f^{\prime}(k)=\infty$ and $\lim _{k \rightarrow \infty} f^{\prime}(k)=0$;

c) the marginal productivity of labor $Q_{L}=f(k)-k f^{\prime}(k)$ has $\lim _{k \rightarrow 0}=0$ and $\lim _{k \rightarrow \infty}=\infty$.

We also assume that the price of the firm's output is normalized to one, so that both the nominal and the real wage rate can be indicated by w. First of all, we demonstrate that if the firm program is:

$$
\text { Maximize }[Q(K, L)-w L]
$$

subject to $Q(K, L) \geq 0$

then there are no limits to the expansion of capital, which means that no finite capital-labor ratio exists in equilibrium. To see this, let us form the Lagrangian function:

$$
\mathfrak{I}=Q(K, L)-w L+\lambda Q
$$

where $\lambda$ is a Lagrangian multiplier. The Kuhn-Tucker conditions state that in equilibrium we have:

$$
\frac{\partial \mathfrak{I}}{\partial K}=Q_{K}+\lambda Q_{K}=0 \rightarrow(1+\lambda) Q_{K}=0
$$




$$
\begin{aligned}
& \frac{\partial \mathfrak{I}}{\partial L}=Q_{L}-w+\lambda Q_{L}=0 \rightarrow(1+\lambda) Q_{L}=w \\
& \frac{\partial \mathfrak{I}}{\partial \lambda}=Q \geq 0, \quad \lambda \geq 0, \quad \lambda Q=0
\end{aligned}
$$

Clearly we see that if $Q>0$, which means that the firm produces something, from (5) we have $\lambda=0$, so as equation (3) reduces to $Q_{K}=0$ and equation (4) to $Q_{L}=w$. Thus, while equation (4) states a limit to the decreasing of the marginal productivity of labor, which cannot fall under the level of the real wage rate, from equation (3) it follows that no limits to capital accumulation exist in this problem. Given that $Q_{K}=f^{\prime}(k) \rightarrow 0$ for $k \rightarrow \infty$ and $Q_{L}=f(k)-k f^{\prime}(k) \rightarrow \infty$ for $k \rightarrow \infty$, it follows that no finite $k$ exists which maximizes the profit of the firm.

Under the same conditions, no equilibrium exists for the revenue maximizing firm too. To see this, let the firm maximization program be:

$$
\text { Maximize } Q(K, L)
$$

subject to $Q(K, L)-w L \geq 0$

where $Q-w L \geq 0$ can be interpreted as the non bankruptcy constraint. The Lagrangian of this problem takes the form:

$$
\mathfrak{I}=Q(K, L)+\lambda[Q(K, L)-w L]
$$

from which we derive the following Kuhn-Tucker conditions:

$$
\begin{aligned}
& \frac{\partial \mathfrak{I}}{\partial K}=Q_{K}+\lambda Q_{K}=0 \rightarrow(1+\lambda) Q_{K}=0 \\
& \frac{\partial \mathfrak{I}}{\partial L}=Q_{L}+\lambda Q_{L}-\lambda w=0 \rightarrow Q_{L}+\lambda\left(Q_{L}-w\right)=0 \\
& \frac{\partial \mathfrak{I}}{\partial \lambda}=Q-w L \geq 0, \lambda \geq 0, \lambda(Q-w L)=0
\end{aligned}
$$

If the non bankruptcy constraint is not binding, that is if $Q-w L>0$, which implies $f(k)>w$, then from (10) we deduce that $\lambda=0$. In this case, from equation (8) we have $Q_{K}=0$ and from equation (9) we have $Q_{L}=0$. These conditions are not consistent, because the former is satisfied for $k \rightarrow \infty$, while the latter for $k \rightarrow 0$. On the contrary, if the non bankruptcy constraint is binding, that is if $Q=w L$, which implies $f(k)=w$, then from (10) we deduce that $\lambda>0$. In this case, from equation (8) we again have $Q_{K}=0$, while from equation (9) we obtain $\lambda=Q_{L} /\left(w-Q_{L}\right)$. But, once again, the capital-labor ratio $k=k_{w}$ for which the condition $f\left(k_{w}\right)=w$ is satisfied is not an equilibrium ratio, because we have $Q_{K}=f\left(k_{w}\right)>0$, while equation (8) requires that $Q_{K} \rightarrow 0$.

This inconsistency depends on the fact that, if no rental market price exists for capital, the firm takes advantage of accumulating capital without limits. So, the only way to avoid that is to fix the level of capital $K_{0}$. If we do that, the problem becomes definite, both for the profit maximizing firm and for the revenue maximizing one.

For the profit maximizing firm, the Lagrangian function is maximized only with respect to the labor factor, while capital stays constant. In this case, from equation (4), when $Q>0$ and $\lambda=0$, we have:

$$
Q_{L}=f(k)-k f^{\prime}(k)=w
$$

which is the well known rule of the profit maximizing firm that equates the marginal productivity of labor to the real wage rate. In the same way, for the revenue maximizing firm, if $f(k)>w$, so as from (10) we have $\lambda=0$, then from (9) we obtain $Q_{L}=0$, which implies, according to assumption $\mathrm{c}$ ), that $k=0$. In this case, the firm does not produce anything. On the contrary, if the firm does produce something, it must be:

$$
\frac{Q}{L}=f(k)=w
$$

Therefore, we can conclude that the rule for a profit maximizing firm is given by equation (11), and the capital-labor ratio that satisfies it can be indicated with $\hat{k}$, so that we can write:

$$
f(\hat{k})-\hat{k} f^{\prime}(\hat{k})=w
$$

whereas the rule for a revenue maximizing firm is given by equation (12) and the capital-labor ratio that satisfies

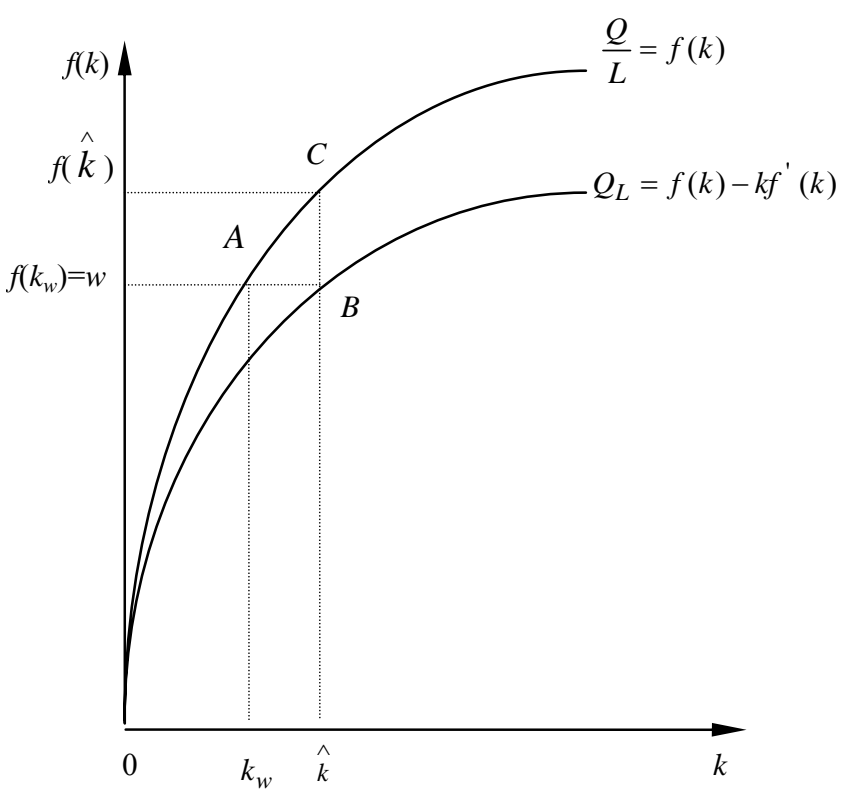

Figure 1. The average productivity of labor function $f(k)$ and the marginal productivity of labor function $f(k)$ $k f^{\prime}(k)$ with respect to the capital-labor ratio $k$ 
it can be indicated with $k_{w}$, so that we have:

$$
f\left(k_{w}\right)=w
$$

Both these conditions are shown in figure 1, where the functions $f(k)$ and $Q_{L}=f(k)-k f^{\prime}(k)$ are depicted. Since $f^{\prime}(k)>0$, we deduce that $Q_{L}$ always stays below $f(k)$. Once the real wage rate $w$ and the level of capital $K_{0}$ are given, the profit maximizing firm is in equilibrium at the point $B$, where $f(\hat{k})-\hat{k} f^{\prime}(\hat{k})=w$. In this point, the output per worker is $f(\hat{k})$, so the profit per worker is given by the difference:

$$
f(\hat{k})-w=\hat{k} f^{\prime}(\hat{k})
$$

If we indicate with $r$ the rate of profit or the rate of net return on capital, so that:

$$
r=\frac{Q-w L}{K}=\frac{f(k)-w}{k}
$$

then, from equation (15) we deduce that the maximum rate of profit $\hat{r}$ is given by:

$$
\hat{r}=\frac{f(\hat{k})-w}{\hat{k}}=f^{\prime}(\hat{k})
$$

which says that $\hat{r}$ is equal to the marginal productivity of capital corresponding to the optimal capital-labor ratio $\hat{k}$. A revenue maximizing firm is in equilibrium at point $A$, where the average productivity of labor equals the real wage rate, that is $f\left(k_{w}\right)=w$. At this point the profit rate is zero, as we have:

$$
r_{w}=\frac{f\left(k_{w}\right)-w}{k_{w}}=0
$$

Each level of $w$ corresponds to a minimum capitallabor ratio $k_{w}$ for which we have a null rate of profit. Given the amount of capital, the firm employs more labor if it maximizes revenue than if it maximizes profits; and this explains why the equilibrium ratio $k_{w}$ is smaller than the profit maximizing one $\hat{k}$. If $w$ increases, both ratios $k_{w}$ and $\hat{k}$ increase, and their difference increases too.

\subsection{The Equilibrium Conditions with a Mini- mum Acceptable Return on Capital Constraint}

If we introduce a minimum acceptable return on capital constraint of the form:

$$
\frac{Q-w L}{K_{0}}=\frac{f(k)-w}{k} \geq r_{0}
$$

then a revenue maximizing firm solves the following maximization program:

$$
\text { Maximize } Q\left(K_{0}, L\right)
$$

subject to $Q\left(K_{0}, L\right)-w L \geq r_{0} K_{0}$.

The Lagrangian of this problem is:

$$
\mathfrak{I}=Q\left(K_{0}, L\right)+\lambda\left[Q\left(K_{0}, L\right)-w L-r_{0} K_{0}\right]
$$

from which we derive the following Kuhn-Tucker conditions:

$$
\frac{\partial \mathfrak{I}}{\partial L}=Q_{L}+\lambda\left(Q_{L}-w\right)=0
$$

$$
\frac{\partial \mathfrak{I}}{\partial \lambda}=\left(Q-w L-r_{0} K_{0}\right) \geq 0, \lambda \geq 0, \lambda\left(Q-w L-r_{0} K_{0}\right)=0
$$

If the constraint is not binding, that is if $Q-w L-r_{0} K_{0}>0$, from (23) we have $\lambda=0$ and from equation (22) we deduce that $Q_{L}=0$, hence the firm does not produce anything. If on the contrary the firm does produce something, the constraint is binding, so that $Q-w L-r_{0} K_{0}=0$ and $\lambda>0$. In this case, from equation (22) we have:

$$
\lambda=\frac{Q_{L}}{w-Q_{L}}
$$

while, from the condition $Q-w L-r_{0} K_{0}=0$, we have:

$$
\frac{Q-w L}{K_{0}}=r_{0}
$$

which says that the rate of return on capital must be equal to the minimum acceptable rate. This condition can be put in the form:

$$
f(k)-k r_{0}=w
$$

If we consider that the range of $r_{0}$ is:

$$
0 \leq r_{0} \leq f^{\prime}(k)
$$

it follows that the curve $f(k)-k r_{0}$ has an intermediate mapping between $f(k)$ and $f(k)-k f^{\prime}(k)$, as it is depicted in figure 2(a). Given the level of capital $K_{0}$, the real wage rate $w$ and the minimum acceptable return on capital $r_{0}$, the equilibrium point of a revenue maximizing firm is no more $A$, but $A$, where equation (26) is satisfied. Let $k_{0}=K_{0} / L_{0}$ be the capital-labor ratio which satisfies equation (26), in point $A^{\prime}$ the output per worker of the firm is $f\left(k_{0}\right)$. Clearly, at this point the rate of return on capital is:

$$
r_{0}=\frac{f\left(k_{0}\right)-w}{k_{0}}
$$

where $k_{w} \leq k_{0} \leq \hat{k}$. When $r_{0}$ varies between zero and 
$f^{\prime}(k)$, the equilibrium point $A^{\prime}$ ranges between $A$ and $B$, while the equilibrium capital-labor ratio ranges between $k_{w}$ and $\hat{k}$. In figure $2(b)$, both the revenue-capital ratio $Q / K_{0}$ (which is equal to the output-capital ratio, because $P=1$ ) and the rate of profit $r$ are depicted. The rate of profit varies with respect to $k$ according to the rule:

$$
r(k)=\frac{f(k)-w}{k}
$$

For each level of $w$ and $K_{0}$, the rate of profit varies as follows. In the interval $0 \leq k<k_{w}$, it is negative and increases with respect to $k$, ranging from $-\infty$ to zero. In the interval $k_{w} \leq k \leq \hat{k}$, it is positive and increasing, and

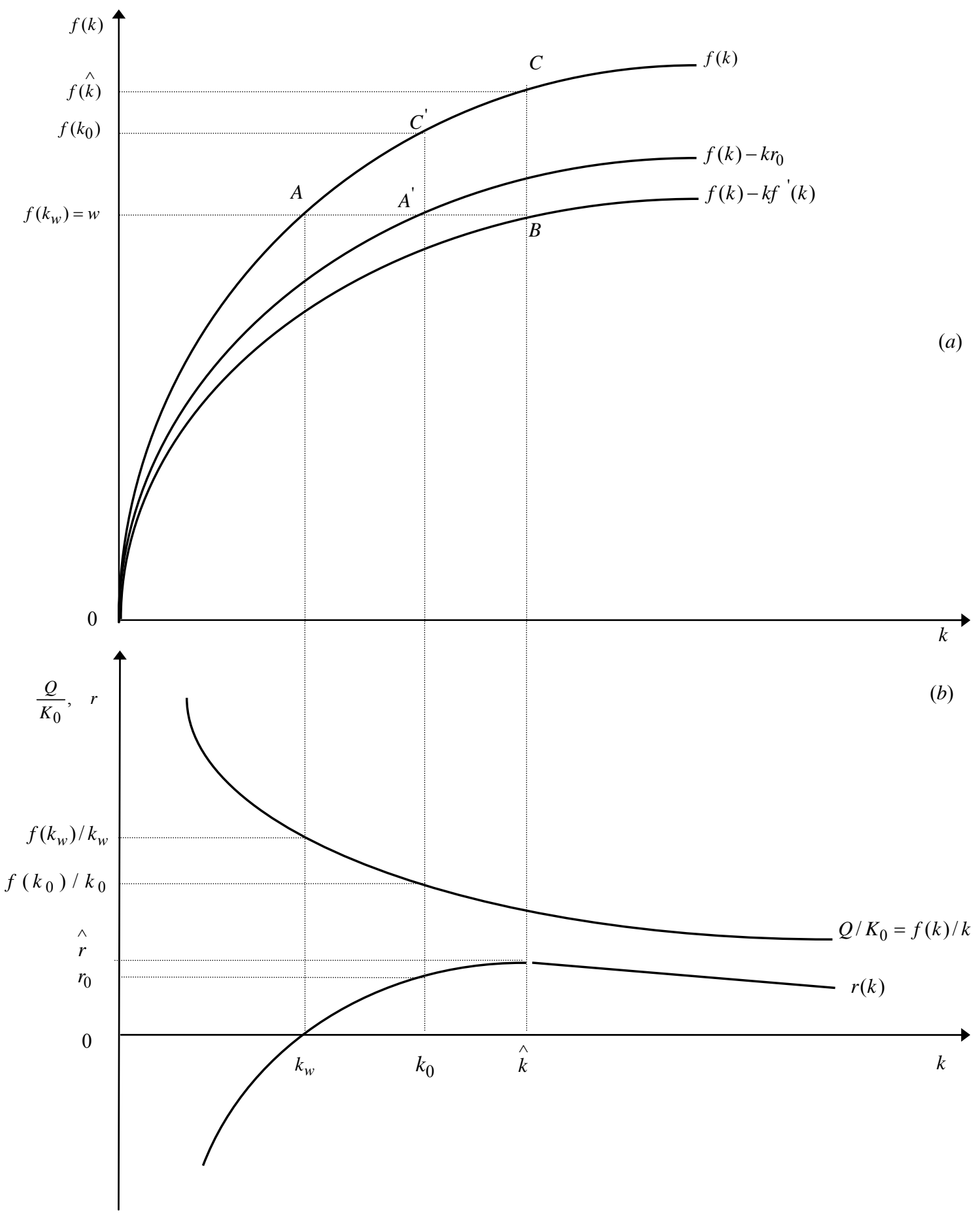

Figure 2. The mapping of the revenue-capital ratio (output-capital ratio) $Q / K_{0}$ and the rate of profit $r(k)$ with respect to $k$ 
varies between zero and its maximum value $\hat{r}$ given by:

$$
\hat{r}=\frac{f(\hat{k})-w}{\hat{k}}
$$

Finally, in the interval $\hat{k}<k<\infty$, it is positive and decreasing, and tends asymptotically to zero for $k \rightarrow \infty$.

From figure $2(b)$, we see that for $k=k_{w}$ the rate of profit $r$ is zero, for $k=\hat{k}$ it takes the maximum value $\hat{r}$, while for $k=k_{0}$ it equals $r_{0}$. In figure $2(b)$, the revenue-capital ratio or output-capital ratio $Q / K_{0}=f(k) / k$ is also depicted. Given the level of capital $K_{0}$, this increases with respect to $L$, so it decreases with respect to the capital-labor ratio $k$. Using de L'Hôpital's rule we have:

$$
\begin{aligned}
& \lim _{k \rightarrow 0} \frac{f(k)}{k}=\lim _{k \rightarrow 0} \frac{\frac{d}{d k} f(k)}{\frac{d}{d k} k}=\lim _{k \rightarrow 0} f^{\prime}(k)=\infty \\
& \lim _{k \rightarrow \infty} \frac{f(k)}{k}=\lim _{k \rightarrow \infty} f^{\prime}(k)=0
\end{aligned}
$$

so the ratio $f(k) / k$ ranges between infinity and zero for $0<$ $k<\infty$. Furthermore, we can check if the sign of its derivative is negative:

$$
\frac{d}{d k} \frac{f(k)}{k}=-\left[f(k)-k f^{\prime}(k)\right] / k^{2}<0
$$

But for $k<k_{w}$ the ratio $Q / K_{0}=f(k) / k$ does not make sense, because it does not respect the non bankruptcy constraint. On the contrary, for $k \geq k_{w}$, this ratio is economically meaningful and decreases with $k$, tending asymptotically to zero as $k \rightarrow \infty$. Hence, its maximal economically meaningful value $Q_{w} / K_{0}=f\left(k_{w}\right) / k_{w}$ corresponds to a capital-labor ratio equal to $k_{w}$.

Therefore, once the level of capital $K_{0}$ is given, if the objective function of the firm is to maximize profits, this corresponds to maximize the rate of profit. In this case, the optimal quantity of labor to be employed is $\hat{L}$ for which $\hat{k}=K_{0} / \hat{L}$ and the equilibrium point is $B$ in figure $2(a)$. On the contrary, if the objective function of the firm is to maximize revenue, this corresponds to maximize the revenue or output per unit of capital. In this case, the optimal quantity of labor to be employed is $L_{w}>\hat{L}$ for which $k_{w}=K_{0} / L_{w}$ and $k_{w}<\hat{k}$. Then, the equilibrium point is $A$ in figure 2(a), which corresponds to the maximum level of employment compatible with the respect of the non bankruptcy constraint.

If the revenue maximizing firm must respect a mini- mum acceptable return on capital constraint of the form $r$ $\geq r_{0}$, then the equilibrium point is $A^{\prime}$ in figure $2(a)$, where $f(k)-k r_{0}=w$. Given the level of capital $K_{0}$, the employment in point $A^{\prime}$ is equal to $L_{0}$ for which $\hat{L} \leq L_{0} \leq L_{w}$ and $k_{0}=K_{0} / L_{0}$. Therefore, in this point equation (28) is verified.

Thus, if $r_{0}$ increases from zero to $\hat{r}$, the equilibrium point $A^{\prime}$ moves along the segment $A B$, going away from point $A$ to point $B$. Point $A^{\prime}$ is as far from point $A$ as higher the minimum acceptable return on capital $r_{0}$ is. An optimal level of the capital-labor ratio $k_{0}$ for which $k_{w} \leq k_{0} \leq \hat{k}$ corresponds to each predetermined level of $r_{0}$. Given the level of capital $K_{0}$, this also corresponds to an employment level $L_{0}$ for which $\hat{L} \leq L_{0} \leq L_{w}$, where $L_{w}$ is the maximum level of employment compatible with the respect to the non bankruptcy constraint and $\hat{L}$ is the level of employment that maximizes the rate of profit. Introducing a minimum acceptable rate of return on capital amounts to introduce a limit to the expansion of the production and the employment of the firm.

\subsection{A Generalization of the Static Theory of a Revenue Maximizing Firm}

Once we have proven that, given the absolute value of capital $K_{0}$, the profit maximization of a firm amounts to the maximization of the rate of profit (or the rate of return on capital), while the maximization of the revenue amounts to the maximization of the revenue (or output) per unit of capital, these results can be generalized for each given level of capital $K_{0}$. So, the equilibrium conditions, both for a profit or for a revenue maximizing firm, become independent from the absolute value of capital and labor employed in the production process. They only depend on the capital-labor ratio. Therefore, if we define:

$$
r=\frac{Q-w L}{K}=\frac{f(k)-w}{k}
$$

as the rate of profit (or the rate of net return on capital), then the program of a profit maximizing firm becomes:

$$
\text { Maximize } \frac{Q-w L}{K}
$$

subject to $\frac{Q}{K} \geq 0$

The Lagrangian of this problem takes the form:

$$
\mathfrak{I}=\frac{Q-w L}{K}+\lambda \frac{Q}{K}
$$

from which the following Khun-Tucker conditions can be derived: 


$$
\begin{gathered}
\frac{\partial \mathfrak{I}}{\partial K}=\frac{K Q_{K}-(Q-w L)}{K^{2}}+\frac{\lambda K Q_{K}-\lambda Q}{K^{2}}=0 \\
\frac{\partial \mathfrak{I}}{\partial L}=\frac{Q_{L}-w}{K}+\frac{\lambda Q_{L}}{K}=0 \\
\frac{\partial \mathfrak{I}}{\partial \lambda}=\frac{Q}{K} \geq 0, \lambda \geq 0, \lambda \frac{Q}{K}=0
\end{gathered}
$$

Equations (37) and (38) can also be stated in the form:

$$
\begin{aligned}
& (1+\lambda)\left[Q-K Q_{K}\right]=w L \\
& (1+\lambda) Q_{L}=w
\end{aligned}
$$

If the firm produces, then $Q / K>0$ and from equation (39) we deduce that $\lambda=0$, thus equations (40) and (41) take the form:

$$
\begin{aligned}
& Q-K Q_{K}=w L \rightarrow f(k)-k f^{\prime}(k)=w \\
& Q_{L}=f(k)-k f^{\prime}(k)=w
\end{aligned}
$$

These two equations state the same maximization rule, corresponding to the equality of the marginal productivity of labor to the real wage rate. This again re-asserts that the equilibrium capital-labor ratio for a profit maximizing firm is $\hat{k}$.

Likewise, the program of a revenue maximizing firm becomes:

$$
\operatorname{Maximize} \frac{Q}{K}
$$

subject to $\frac{Q-w L}{K} \geq 0$

where the firm respects a non bankruptcy constraint. To solve this problem, let us form the Lagrangian function:

$$
\mathfrak{I}=\frac{Q}{K}+\frac{\lambda(Q-w L)}{K}
$$

from which the following Kuhn-Tucker conditions can be derived:

$$
\begin{aligned}
& \frac{\partial \mathfrak{I}}{\partial K}=\frac{K Q_{K}-Q}{K^{2}}+\frac{\lambda\left[K Q_{K}-(Q-w L)\right]}{K^{2}}=0 \\
& \frac{\partial \mathfrak{I}}{\partial L}=\frac{Q_{L}}{K}+\frac{\lambda\left(Q_{L}-w\right)}{K}=0 \\
& \frac{\partial \mathfrak{I}}{\partial \lambda}=\frac{Q-w L}{K} \geq 0, \lambda \geq 0, \frac{\lambda(Q-w L)}{K}=0
\end{aligned}
$$

Equations (46) and (47) can be put in the form:

$$
\begin{aligned}
& (1+\lambda)\left(Q-K Q_{K}\right)=\lambda w L \\
& (1+\lambda) Q_{L}=\lambda w
\end{aligned}
$$

respectively. If the non bankruptcy constraint is not bind- ing, that is if $Q-w L>0$, then from (48) we deduce $\lambda=0$. In this case, from equation (50) we have $Q_{L}=0$, which implies:

$$
Q_{L}=f(k)-k f^{\prime}(k)=0
$$

or:

$$
f(k)=k f^{\prime}(k)
$$

This last equation is satisfied only for $k=0$, that is, when the firm does not produce anything. Analogously, for $\lambda=0$, also equation (49) leads to the same conclusion. In fact, if $\lambda=0$, then $Q=K Q_{K}$, and dividing by $L$ we obtain (52). It follows that, if the firm produces, the non bankruptcy constraint must be binding, which implies:

$$
Q-w L=0 \rightarrow f(k)=w
$$

In this case, from (48) we deduce that $\lambda>0$ and the value of $\lambda$ can be determined either from (49) or (50). Using the latter, we have:

$$
(1+\lambda)\left[f(k)-k f^{\prime}(k)\right]=\lambda f(k)
$$

The same result is obtained from (49) dividing by $L$. From (54) we have:

$$
\lambda=\frac{f(k)-k f^{\prime}(k)}{k f^{\prime}(k)}=\frac{Q_{L}}{k Q_{K}}
$$

which defines the equilibrium value of $\lambda$. Equation (55) can also be put in the form:

$$
M R S_{L / K}=\frac{Q_{L}}{Q_{K}}=\lambda k
$$

where $M R S_{L / K}$ stays for the marginal rate of substitution between labor and capital. If we interpret $\lambda$ as the shadow price of capital, then (56) means that in equilibrium the marginal rate of substitution must equal the shadow value of per capita capital. As we shall see later, this rule also applies in a dynamic analysis. Because equations (53) and (56) are satisfied for $k=k_{w}$, it is confirmed that the equilibrium capital-labor ratio for a revenue maximizing firm is $k_{w}$, that is the value of $k$ which guaranties the equality between the average productivity of labor and the real wage rate.

Finally, if the firm must satisfy a minimum return on capital constraint, the maximization program is as follows:

$$
\text { Maximize } \frac{Q}{K}
$$

subject to $\frac{Q-w L}{K} \geq r_{0}$

where $r_{0}$ is the minimum acceptable rate of return on capital. The Lagrangian of this problem is:

$$
\mathfrak{I}=\frac{Q}{K}+\lambda\left[\frac{Q-w L}{K}-r_{0}\right]
$$


from which we derive the following Kuhn-Tucker conditions:

$$
\begin{aligned}
& \frac{\partial \mathfrak{I}}{\partial K}=\frac{K Q_{K}-Q}{K^{2}}+\lambda\left[\frac{K Q_{K}-(Q-w L)}{K^{2}}\right]=0 \\
& \frac{\partial \mathfrak{I}}{\partial L}=\frac{Q_{L}}{K}+\frac{\lambda\left(Q_{L}-w\right)}{K}=0 \\
& \frac{\partial \mathfrak{I}}{\partial \lambda}=\frac{Q-w L}{K}-r_{0} \geq 0, \lambda \geq 0, \lambda\left[\frac{Q-w L}{K}-r_{0}\right]=0
\end{aligned}
$$

Given that equations (59) and (60) are similar, respectively, to equations (46) and (47), they can again be put in the form of equations (49) and (50). From (61) we can conclude that, if the minimum rate of return on capital constraint is not binding, then $\lambda=0$. In this case, equations (51) and (52) follow, and $k=0$. On the contrary, if the firm does produce, the minimum rate of return on capital constraint must be binding. Therefore, it must be:

$$
r_{0}=\frac{Q-w L}{K}=\frac{f(k)-w}{k}
$$

or

$$
f(k)-k r_{0}=w
$$

and $\lambda$ is positive. In this case, either from (49) or (50), we conclude that

$$
(1+\lambda)\left[f(k)-k f^{\prime}(k)\right]=\lambda\left[f(k)-k r_{0}\right]
$$

and

$$
\lambda=\frac{f(k)-k f^{\prime}(k)}{k\left[f^{\prime}(k)-r_{0}\right]}=\frac{Q_{L}}{k\left(Q_{K}-r_{0}\right)}
$$

which is positive for $k<\hat{k}$, as the difference $f^{\prime}(k)-r_{0}=Q_{K}-r_{0}$ is also positive.

Equation (65) can be put in the form:

$$
N M R S_{L / K}\left(r_{0}\right)=\frac{Q_{L}}{Q_{K}-r_{0}}=\lambda k
$$

which states the equilibrium condition for a revenue maximizing firm in the case that a minimum rate of return on capital constraint must be satisfied. In this case, the equilibrium rule becomes the equality of the net marginal rate of substitution between labor and capital $\left(N M R S_{L / K}\right)$, which is a function of $r_{0}$, to the shadow value of per capita capital $\lambda k$. Now, the $N M R S_{L / K}$ is defined as the ratio of the marginal productivity of labor over the marginal productivity of capital net of the minimum acceptable rate of return $r_{0}$.

Since equations (63) and (66), as is shown in figure 2, are satisfied for $k=k_{0}$, it is confirmed that the equilibrium capital-labor ratio for a revenue maximizing firm, when a minimum rate of return on capital constraint must be satisfied, is $k=k_{0}$. To this value of $k$ we have the balance between the average productivity of labor, net of the minimum acceptable rate of return on capital, and the real wage rate. This condition is also obtained in the following dynamic analysis.

\section{The Dynamic Analysis of the Revenue Maximizing Firm}

\subsection{The Equilibrium Conditions without a Minimum Acceptable Return on Capital Con- straint}

In the dynamic analysis, $K, L$ and $Q$ are all functions of time $t$. Therefore, the instant dynamic production function is

$$
Q=Q[K(t), L(t)]
$$

where $Q$ has the same properties as in $a$ )-c) of section 2.1. Let $P$ be the price of the output, so the instant revenue is $P Q$. The objective function of a revenue maximizing firm then is the present value $(P V)$ of all future revenues, that is

$$
P V=\int_{0}^{\infty} P Q[K(t), L(t)] e^{-\rho t} d t
$$

where $\rho$ is the instantaneous discount rate.

The dynamics of capital accumulation can be defined as follows:

$$
\dot{K}=\alpha\{P Q[K(t), L(t)]-W L\}
$$

where $\dot{K}=d K / d t$ is the net instantaneous investment (there is no depreciation of capital), while $W$ is the nominal wage rate. Finally, $0 \leq \alpha \leq 1$ is the share of instantaneous profits the firm decides to accumulate.

Normalizing $P=1$ so as $w=W / P=W$ indicates both the real and the nominal wage rate, equation (69) must satisfy the condition:

$$
\dot{K}=\alpha(Q-w L) \geq 0
$$

which is both the law of motion of capital and the instantaneous non bankruptcy constraint.

Starting from an initial level of capital $K_{0}$, the program of the revenue maximizing firm is

$$
\text { Maximize } \int_{0}^{\infty} Q(K, L) e^{-\rho t} d t
$$

subject to $\dot{K}=\alpha(Q-w L) \geq 0,0 \leq \alpha \leq 1$, and $K(0)=K_{0}$, $K_{\infty}$ free, $K_{0}, w$ given. 
In this problem, $K$ is the state variable while $L$ is a control variable. What about $\alpha$, which is the share of instantaneous profits the firm decides to accumulate? ${ }^{4}$ In fact, we can suppose that the firm can decide in each instant of time to accelerate the speed of capital accumulation by increasing the value of $\alpha$. We have the maximum speed if $\alpha=1$, while there is no capital accumulation if $\alpha=0$. In the latter case, all profits are distributed to the stockholders. Hence, it is obvious to consider $\alpha$ as a second control variable of the problem.

To solve the program (71), let us indicate with $H_{C}$ the current value Hamiltonian:

$$
H_{C}=Q(K, L)+\lambda \alpha(Q-w L)
$$

where $\lambda$ is a dynamic Lagrangian multiplier. Furthermore, as the costate variable is strictly adherent to the state variable $K, \lambda$ can also be interpreted as the shadow price of capital.

Because the Hamiltonian is linear with respect to $\alpha$, the maximization rule $\partial H_{C} / \partial \alpha=0$ does not apply in this case. Instead, we have a maximum in one of the extreme values of the $\alpha$ interval $[0,1]$. Moreover, since $\lambda$ is positive, as we will see later, $H_{C}$ is maximized for $\alpha=1$ if $Q-w L>0$, while, for $Q-w L=0, \alpha$ is indeterminate. Furthermore, since $Q$ is a strictly quasi-concave function, the Hamiltonian $H_{C}$ is a concave function of $K$ and $L$. So, the following conditions of the maximum principle are necessary and sufficient for the solution of the program (71):

$$
\begin{aligned}
& \frac{\partial H_{C}}{\partial L}=Q_{L}+\lambda \alpha\left(Q_{L}-w\right)=0 \\
& \dot{K}=\frac{\partial H_{C}}{\partial \lambda}=\alpha(Q-w L) \\
& \dot{\lambda}=-\frac{\partial H_{C}}{\partial K}+\rho \lambda=-Q_{K}-\lambda \alpha Q_{K}+\rho \lambda \\
& \lim _{t \rightarrow \infty} H_{C} e^{-\rho t}=0, \lim _{t \rightarrow \infty} \lambda e^{-\rho t}=0
\end{aligned}
$$

Condition (73) guarantees the employment of the labor factor is optimized along the time path $L(t)$. If the firm does make profits, $Q-w L>0$ and $\alpha=1$, and from condition (73) we obtain:

$$
\lambda=\frac{Q_{L}}{w-Q_{L}}=\frac{f(k)-k f^{\prime}(k)}{w-\left[f(k)-k f^{\prime}(k)\right]}
$$

This is the dynamic optimization rule the firm follows

\footnotetext{
${ }^{4}$ In Leland's model [28], $\alpha$ is an exogenous parameter on which the firm exerts no influence. This assumption is not realistic and, at the same time, it contributes to limit Leland's analysis.
}

in the employment of the labor factor, which corresponds to condition (9) and conditions (22) or (24) from a static point of view. This rule requires that the firm must balance the ratio of the marginal productivity of labor over the wage rate, net of the same marginal productivity of labor, to the shadow price of capital along the entire time path of the costate variable $\lambda$.

Condition (74) again represents the dynamics of capital, while condition (75) is the equation of motion of the costate variable $\lambda$. Equations (74) and (75) together form the Hamiltonian or canonical system.

Finally, equations (76) are the transversality conditions. The first one requires the limit of the present-value Hamiltonian vanishes as $t \rightarrow \infty$. The second one requires the shadow price of capital in discounted value vanishes as $t \rightarrow \infty$. Since the term $e^{-\rho t} \rightarrow 0$ as $t \rightarrow \infty$, both these transversality conditions are satisfied for finite values of $H_{C} \neq 0$, and $\lambda \neq 0$. This will be demonstrated in section 3.4.

Condition (74), dividing by $L$ and remembering that $\alpha=1$, can be put in the form:

$$
\frac{\dot{K}}{L}=f(k)-w
$$

Since from the definition of $k=K / L$ we have $K=k L$, and $\dot{K}=\dot{k} L+k \dot{L}$, dividing by $L$ and substituting we obtain:

$$
\frac{\dot{K}}{L}=\dot{k}+k \frac{\dot{L}}{L}=f(k)-w
$$

and finally:

$$
\dot{k}=f(k)-w-k \frac{\dot{L}}{L}
$$

Given the real wage rate $w$, equation (80) describes the dynamics of the capital-labor ratio as a function of the rate of growth of employment $\dot{L} / L$. Analogously, from condition (75), setting $\alpha=1$, we obtain:

$$
\dot{\lambda}=\lambda\left[\rho-f^{\prime}(k)\right]-f^{\prime}(k)
$$

which describes the dynamics of $\lambda$, given $\rho$, as a function of the capital-labor ratio.

Conditions (77), (80) and (81), taken together, form a system of three equations, two of which are differential equations, in three unknowns, given by $k, \lambda$ and $\dot{L} / L$. These equations fully describe the dynamics of a revenue maximizing firm. Given the real wage rate $w$ and the discount rate $\rho$, we can find a steady state equilibrium for $\dot{k}=\dot{\lambda}=0$. This equilibrium is characterized by a time constant value of the triple $(k, \lambda, \dot{L} / L)$. Furthermore, our system can be decomposed into two sub-systems: the first one made up by equations (77) and (81), where the variable $\dot{L} / L$ does not appear, and the second one corre- 
sponding to equation (80) alone, which is the only equation where the employment rate of growth $\dot{L} / L$ is present. So, the first subsystem made up by equations (77) and (81) can be solved autonomously, and its solution gives, for $\dot{\lambda}=0$, the steady state values of $k$ and $\lambda$. Substituting the equilibrium value of $k$ in equation (80) and setting $\dot{k}=0$, the second subsystem yields the equilibrium growth rate of employment $\dot{L} / L$.

Now, let us concentrate, first of all, on the subsystem made up by equations (77) and (81), which can be depicted in a phase diagram on the plane $k, \lambda$. To construct this, we must pay attention to equation (77). Like in the static analysis, let us indicate with $\hat{k}$ the capital-labor ratio which satisfies the equality between the marginal productivity of labor and the real wage rate, that is $Q_{L}=f(\hat{k})-\hat{k} f^{\prime}(\hat{k})=w$; and let us indicate with $k_{w}$ the capital-labor ratio which satisfies the equality between the average productivity of labor and the real wage rate, that is $f\left(k_{w}\right)=w$. From equation (77), since $Q_{L} \rightarrow 0$ as $k \rightarrow 0$, whereas the ratio $Q_{L} /\left(w-Q_{L}\right) \rightarrow \infty$ as $\left(w-Q_{L}\right) \rightarrow 0$ and $k \rightarrow \hat{k}$, we deduce that $\lambda$ is an increasing function of $k$, which goes from zero to infinity as $k$ goes from zero to $\hat{k}$ Furthermore, we can find that the sign of the derivative of $\lambda$ with respect to $k$ is positive. To find this, let us write equation (77) in the implicit form:

$$
G_{w}(k, \lambda)=f(k)-k f^{\prime}(k)+\lambda\left[f(k)-k f^{\prime}(k)-w\right]=0
$$

where $G_{w}$ is the implicit function existing between $k$ and $\lambda$. The sub-index $w$ in $G$ means that this function is defined for any given $w$. Differentiating (82), we have:

$$
\frac{d \lambda}{d k}=-\frac{\partial G_{w} / \partial k}{\partial G_{w} / \partial \lambda}=\frac{(1+\lambda) k f^{\prime \prime}(k)}{f(k)-k f^{\prime}(k)-w}>0
$$

which is positive because for $k<\hat{k}$ we have $w$ $>f(k)-k f^{\prime}(k)$ and $f^{\prime \prime}(k)<0$.

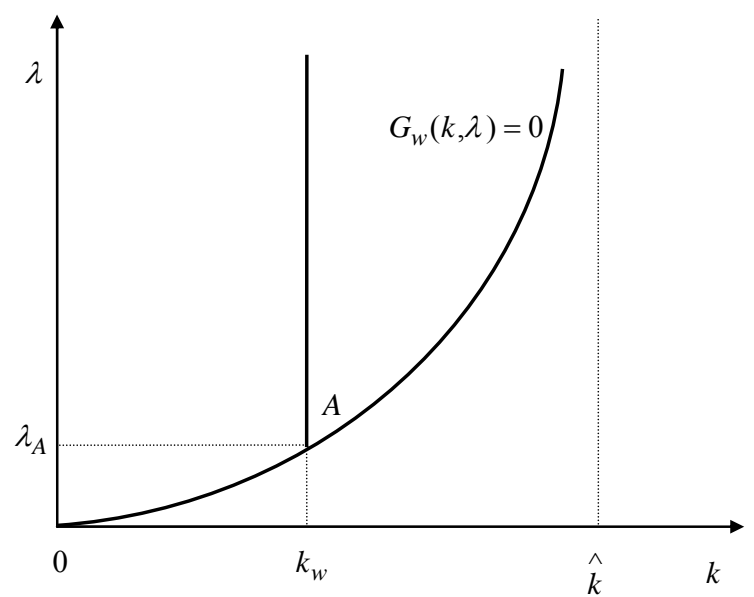

Figure 3. The mapping of the function $G_{w}(k, \lambda)$
However, equation (77) is not economically meaningful for $0 \leq k<k_{w}$, because in this range the non bankruptcy constraint is not satisfied. Anyway, for $k=k_{w}$, the firm does not make profits, so we have $Q-w L=0$ and $\alpha$ is indeterminate in the open range $\alpha \in[0,1)$. In this case, from (73) we obtain:

$$
\lambda=\frac{Q_{L}}{\alpha\left[w-Q_{L}\right]}=\frac{f\left(k_{w}\right)-k_{w} f^{\prime}\left(k_{w}\right)}{\alpha\left[w-f\left(k_{w}\right)+k_{w} f^{\prime}\left(k_{w}\right)\right]}
$$

where $\lambda$ is defined with respect to $\alpha$ for $k=k_{w}$. The mapping of the function $G_{w}(k, \lambda)=0$ is depicted in figure 3 . The part of this function that has an economic meaning belongs to the range $\left[k_{w}, \hat{k}\right)$; for $k=k_{w}$, the function $G_{w}(k, \lambda)=0$ becomes a truncated vertical line, where the truncation point $A$ is given by:

$$
\lambda_{A}=\lim _{k \rightarrow k_{w}} \frac{f(k)-k f^{\prime}(k)}{w-\left[f(k)-k f^{\prime}(k)\right]}
$$

where the limit is calculated as $k \rightarrow k_{w}$ from the right. For $k_{w}<k<\hat{k}$, instead, the curve $G_{w}(k, \lambda)=0$ is defined by the expression (77).

Since the equilibrium condition the firm must respect in employing labor is satisfied only along the curve $G_{w}(k, \lambda)=0$, it follows that the dynamics of the firm can be fully described only by a point of this curve belonging to the range $\left[k_{w}, \hat{k}\right)$. To find this point, we need to take into account condition (81), which describes the dynamics of the shadow price of capital $\lambda$.

The static analysis has suggested that a profit maximizing firm is in equilibrium in $\hat{k}$, while a revenue maximizing firm is in equilibrium in $k_{w}$. Furthermore, if a revenue maximizing firm must also respect a minimum ac

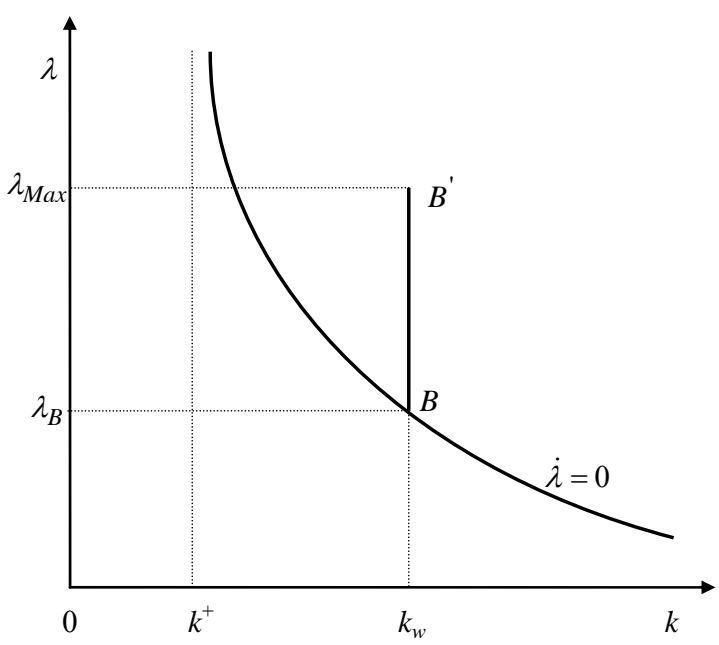

Figure 4. The mapping of the $\dot{\lambda}=0$ curve 
ceptable return on capital constraint, its equilibrium point is intermediate between $k_{w}$ and $\hat{k}$. We are led to an analogous conclusion in a dynamic context too, but with a fundamental specification. As long as the firm grows, the dynamic equilibrium point is intermediate between $k_{w}$

and $\hat{k}$. Once the firm stops growing, the stationary equilibrium of a revenue maximizing firm is the same as the static one and corresponds to a capital-labor ratio equal to $k_{w}$.

When a revenue maximizing firm must also respect a minimum acceptable return on capital constraint in a dynamic context, we have two cases. If the constraint is not binding, in the equilibrium point the firm grows at a rate which is smaller than the rate of profit. Otherwise, if the constraint is binding, the firm does not grow any more. In the latter case, all profits that the firm realizes are distributed to the stockholders to satisfy the minimum acceptable return on capital constraint, and nothing remains to the firm for self-financing and capital accumulation. The equilibrium point $k_{0}$, being $k_{w} \leq k_{0} \leq \hat{k}$, is the capitallabor ratio to which it corresponds a rate of profit exactly equal to the minimum return on capital rate $r_{0}$. Obviously, also in this case the firm rate of growth is zero. We demonstrate all this in the following sections.

\subsection{The Equilibrium Capital-labor Ratio}

As previously seen, the dynamics of the costate variable $\lambda$ is given by equation (81). First we need to map in a phase diagram the stationary points of $\lambda$, given by:

$$
\dot{\lambda}=\lambda\left[\rho-\alpha f^{\prime}(k)\right]-f^{\prime}(k)=0
$$

from which we obtain:

$$
\lambda(\dot{\lambda}=0)=\frac{f^{\prime}(k)}{\rho-\alpha f^{\prime}(k)}
$$

If the firm makes profits, $Q-w L>0$ and $\alpha=1$. In this case, equation (87) reduces to:

$$
\lambda(\dot{\lambda}=0)=\frac{f^{\prime}(k)}{\rho-f^{\prime}(k)}
$$

which describes the stationary points of the shadow price of capital $\lambda$ with respect to the capital-labor ratio $k$. The map of this curve, from now on defined as the $\dot{\lambda}=0$ curve, which is depicted in figure 4 , depends on the value of $\rho$. For $\rho<f^{\prime}(k)$, the curve $\dot{\lambda}=0$ gives negative values of $\lambda$, which are not economically meaningful. Therefore it must be $\rho \geq f^{\prime}(k)$ in order to have significant economic values of $\lambda$.

Let $k^{+}$be the level of $k$ which satisfies the equation $\rho-f^{\prime}\left(k^{+}\right)=0$, so if $k \rightarrow k^{+}$from the right, then we have $\lambda \rightarrow \infty$. Since $f(k)$ decreases with $k$, for $k>k^{+}$we have $\rho-f^{\prime}(k)>0$, and $\lambda>0$, so we have positive values of the shadow price of capital. Furthermore, always for values of $k>k^{+}$, differentiating equation (86), we have:

$$
\frac{d \lambda}{d k}=-\frac{\partial \dot{\lambda} / \partial k}{\partial \dot{\lambda} / \partial \lambda}=\frac{(1+\lambda) f^{\prime \prime}(k)}{\rho-f^{\prime}(k)}<0
$$

The sign of this expression is negative because the denominator is positive, while $f^{\prime \prime}(k)<0$. As $k \rightarrow k^{+}$from the right, $\left[\rho-f^{\prime}(k)\right] \rightarrow 0$, so $d \lambda / d k \rightarrow-\infty$. This means that the curve $\dot{\lambda}=0$ is asymptotic as $k \rightarrow k^{+}$from the right, decreases as $k$ increases and becomes zero as $k \rightarrow \infty$, being $\lim _{k \rightarrow \infty} f^{\prime}(k)=0$.

By definition, the value of $k^{+}$depends on the discount rate $\rho$. For sufficiently high values of $\rho$, we find that $k^{+}$ has an intermediate value between zero and $k_{w}$. In this case, the curve $\dot{\lambda}=0$ is economically meaningful only for $k \geq k_{w}$, that is to say only for those values of $k$ for which the non bankruptcy constraint is satisfied. For $k>k_{w}$, the curve $\dot{\lambda}=0$ is defined by equation (88), while for $k=k_{w}$ the curve is defined by equation (87) with a value of $\alpha$ which varies in the open interval $0 \leq \alpha<1$. In the latter case, the stationary values of $\lambda$ are given by:

$$
\lambda(\dot{\lambda}=0)=\frac{f^{\prime}\left(k_{w}\right)}{\rho-\alpha f^{\prime}\left(k_{w}\right)}
$$

As $\alpha$ varies, equation (90) describes the segment $B B^{\prime}$, whose extreme value at $B^{\prime}$ (obtained for $\alpha=0$ ) is

$$
\lambda_{\text {Max }}=\frac{f^{\prime}\left(k_{w}\right)}{\rho}
$$

while in point $B$ the stationary value of $\lambda$ is given by:

$$
\lambda_{B}=\lim _{k \rightarrow k_{w}} \frac{f^{\prime}(k)}{\rho-f^{\prime}(k)}=\frac{f^{\prime}\left(k_{w}\right)}{\rho-f^{\prime}\left(k_{w}\right)}
$$

where the limit is calculated as $k \rightarrow k_{w}$ from the right. Overlapping the two curves $G_{w}(k, \lambda)=0$ and $\dot{\lambda}=0$ on the same graph, we can depict the phase diagram of our model. We can have many cases, depending on the relative location of the points $A, B$ e $B$ '. For $\lambda_{B}>\lambda_{A}$, where $\lambda_{A}$ is defined by equation (85), we have the situation depicted in figure 5 . In this case, the dynamic equilibrium of a revenue maximizing firm may occur at two points of the capital-labor ratio, corresponding respectively to $\bar{k}$ and $k_{w}$. However, the only dynamic equilibrium is point $E$, to which an endogenous growth of the firm corresponds, which is defined by the pair of values $(\bar{k}, \bar{\lambda})$. 


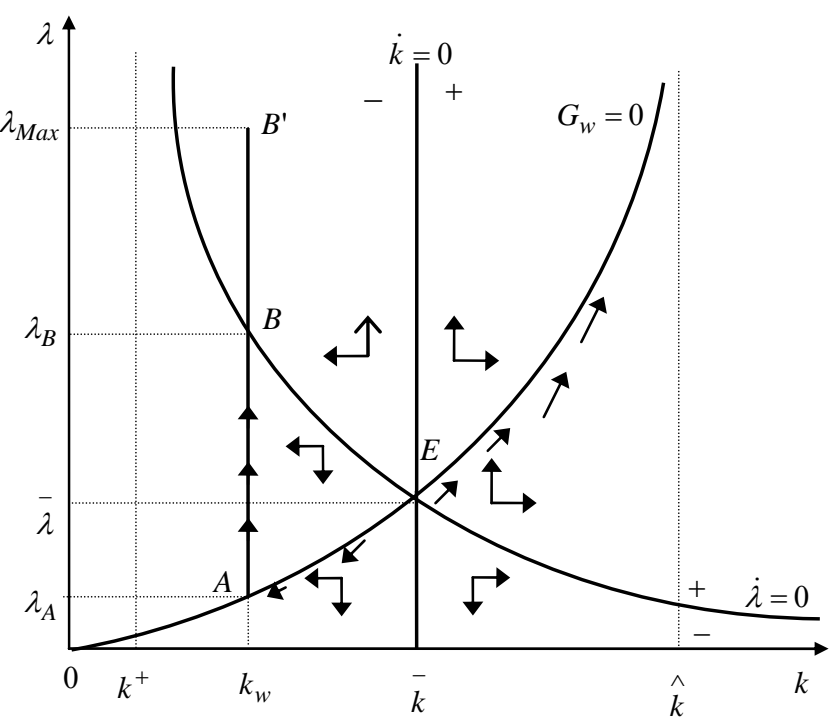

Figure 5. The phase diagram for $0<\boldsymbol{k}^{+}<\boldsymbol{k}_{w}$

At this point, the dynamic equilibrium of a revenue maximizing firm is characterized by the stationarity of both the capital-labor ratio at the level $\bar{k}$ and the shadow price of capital at the level $\bar{\lambda}$. The equilibrium value of the capital-labor ratio $\bar{k}$ can be found taking the equations (77) and (88) as a system of simultaneous equations, whose solution gives:

$$
\frac{f(k)-k f^{\prime}(k)}{w-f(k)+k f^{\prime}(k)}=\frac{f^{\prime}(k)}{\rho-f^{\prime}(k)}
$$

while the equilibrium value of the capital shadow price $\bar{\lambda}$ is given by:

$$
\bar{\lambda}=\frac{f^{\prime}(\bar{k})}{\rho-f^{\prime}(\bar{k})}=\frac{f(\bar{k})-\bar{k} f^{\prime}(\bar{k})}{w-\left[f(\bar{k})-\bar{k} f^{\prime}(\bar{k})\right]}
$$

From equation (93), rearranging we obtain:

$$
\frac{f(k)-k f^{\prime}(k)}{f^{\prime}(k)}=\frac{w}{\rho}
$$

which can be expressed in the form:

$$
M R S_{L / K}=\frac{Q_{L}}{Q_{K}}=\frac{w}{\rho}
$$

where, like in the static analysis, $M R S_{L / K}$ is the rate of marginal substitution between labor and capital. Equation (96) represents the optimizing rule which must be followed by a revenue maximizing firm in a dynamic context. This rule requires that the rate of marginal substitution between labor and capital be equal to the ratio between the real wage rate and the discount rate. Since the marginal productivity of labor increases with respect to the capital-labor ratio, whereas the marginal productivity of capital decreases, the $M R S_{L / K}$ is an increasing func-

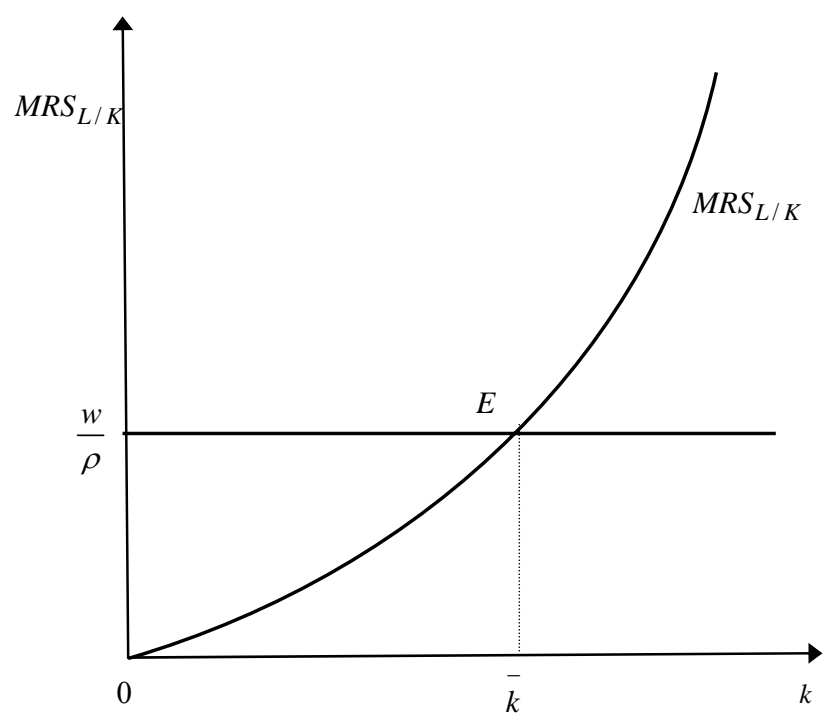

Figure 6. The mapping of the dynamic equilibrium condition $M R S_{L / K}=w / \rho$

tion of $k$. Furthermore, because as $k \rightarrow 0$ we have $Q_{L} \rightarrow 0$ and $Q_{K} \rightarrow \infty$, whereas as $k \rightarrow \infty$ we have $Q_{L} \rightarrow \infty$ and $Q_{K} \rightarrow 0$, it follows that $M R S_{L / K} \rightarrow 0$ as $k \rightarrow 0$ and $M R S_{L / K} \rightarrow \infty$ as $k \rightarrow \infty$. This is shown in figure 6. It is clear from this figure that an increase of the real wage rate $w$ or a decrease of the discount rate $\rho$ imply an increase of the equilibrium capital-labor ratio $\bar{k}$.

In a neighborhood of point $E$ in figure 5 , the value of $\lambda$ tends to depart from its equilibrium value $\bar{\lambda}$. This can be demonstrated by differentiating (81) with respect to $k$ :

$$
\frac{\partial \dot{\lambda}}{\partial k}=-\lambda f^{\prime \prime}(k)-f^{\prime \prime}(k)>0
$$

which is positive, since $f^{\prime \prime}(k)<0$. According to (97), as $k$ increases (going rightwards), $\dot{\lambda}$ should follow the $(-, 0$, + ) sign sequence. So, the $\lambda$-arrowheads must point downward to the left of $\dot{\lambda}=0$ curve, and upward to the right of it. This means that $\dot{\lambda}<0$, implying $\lambda$ decreases with respect to time, on the left of the $\dot{\lambda}=0$ curve, while $\dot{\lambda}>0$, implying $\lambda$ increases with respect to time, on the right of the $\dot{\lambda}=0$ curve.

Since the value of the capital-labor ratio at the point $E$ is constant at the level $\bar{k}$, from (80), which is the second subsystem that describes the dynamics of the revenue maximizing firm, we have:

$$
\dot{k}=f(\bar{k})-w-\bar{k} \frac{\dot{L}}{L}=0
$$

from which we deduce:

$$
\frac{\dot{L}}{L}=\frac{f(\bar{k})-w}{\bar{k}}
$$

Therefore, in the dynamic equilibrium of point $E$, the 
growth rate of employment is given by the return on capital rate corresponding to the equilibrium capital-labor ratio $\bar{k}$. As $\bar{k}$ is stationary, this implies that $K$ grows at the same rate as $L$. Furthermore, the linear homogeneity of the production function implies that $Q$ increases at the same rate, too. Thus, we have:

$$
\frac{\dot{L}}{L}=\frac{\dot{K}}{K}=\frac{\dot{Q}}{Q}=\frac{f(\bar{k})-w}{\bar{k}}=\bar{r}
$$

where $\bar{r}$ is the common growth rate of labor, capital and output.

Therefore, in point $E$ we have a balanced growth of the firm, where the rate of growth $\bar{r}$ is endogenously determined. Therefore, this is a neoclassical endogenous model of the revenue maximizing firm, which goes further beyond Leland's analysis.

There is no transitional dynamics in this model. In fact, if the firm begins its activity with the capital $K(0)=K_{0}$, it must choose from the beginning the level $L_{0}$ of the labor factor for which we have $K_{0} / L_{0}=\bar{k}$ and it must keep permanently fixed this capital-labor ratio. So, the equilibrium time path of $k$ is constant.

Analogously, the equilibrium time path of the shadow price of capital is also constant at the level indicated by (94), whereas the equilibrium time paths of labor, capital and output depend on the rate of endogenous growth $\bar{r}$ as defined by (100). They are defined respectively by the following exponential functions:

$$
\begin{gathered}
L=L_{0} e^{\bar{r} t} \\
K=K_{0} e^{\bar{r} t} \\
Q=Q_{0} e^{\bar{r} t}
\end{gathered}
$$

where, given $K_{0}$, the value of $L_{0}$ is defined by $L_{0}=K_{0} / \bar{k}$, whereas that of $Q_{0}$ is given by $Q_{0}=$ $Q\left(K_{0}, L_{0}\right)$.

The $\dot{k}=0$ curve given by (98) must plot as a vertical straight line in figure 5 , with horizontal intercept $\bar{k}$. In a neighborhood of point $E$ along the $G_{w}(k, \lambda)=0$ curve, the value of $k$, and not only that of $\lambda$, tends to depart from its equilibrium value. This can be demonstrated differentiating (80) with respect to $k$ :

$$
\frac{\partial \dot{k}}{\partial k}=f^{\prime}(k)-\frac{\dot{L}}{L}
$$

Substituting to $\dot{L} / L$ its value given by (99), in a neighborhood of the point $E$ we have:

$$
\frac{\partial \dot{k}}{\partial k}=\frac{w-\left[f(\bar{k})-\bar{k} f^{\prime}(\bar{k})\right]}{\bar{k}}>0
$$

which assumes a positive value because for $\bar{k}<\hat{k}$ the real wage rate is greater than the marginal productivity of labor. This suggests that $\dot{k}$ should follow the $(-, 0,+)$ sign sequence as $k$ increases. Hence the $k$-arrowheads should point leftwards to the left of the $\dot{k}=0$ curve, and rightwards to the right of it. This means that, for $k<\bar{k}$, we have $\dot{k}<0$, so $k$ decreases with respect to time, while for $k>\bar{k}$ we have $\dot{k}>0$, so that $k$ increases with respect to time.

Therefore, along the $G_{w}(k, \lambda)=0$ curve, the arrowheads point rightwards and upward to the right of the point $E$ and they point leftwards and downward to the left of that point. So, both the capital-labor ratio $k$ and the shadow price of capital $\lambda$, when moving along the $G_{w}(k, \lambda)=0$ curve to optimize the use of labor, tend to increase to the right of point $E$ and to decrease to the left. It follows that point $E$ is dynamically unstable, and the firm can remain in equilibrium at that point only if it has chosen to stay there from the beginning.

If, on the contrary, the firm begins its activity with a capital-labor ratio greater than $\bar{k}$, the dynamics of the model suggests that the firm must choose a point on the right of point $E$ along the $G_{w}(k, \lambda)=0$ curve; so, it is induced to over-accumulate capital, approaching asymptotically the capital-labor ratio $\hat{k}$ which maximizes the rate of profit. But, in this case, a dynamically efficient equilibrium point for a revenue maximizing firm does not exist, because when $k$ tends to $\hat{k}$ the shadow price of capital tends to infinity, so it has not a stationary value.

On the contrary, if the firm begins its activity with a capital-labor ratio smaller than $\bar{k}$, the dynamics of the model suggests that the firm must choose a point on the left of the point $E$ along the $G_{w}(k, \lambda)=0$ curve. So, it is induced, following the arrowheads, to under-accumulate capital moving along this curve towards the point $A$. In the point $A$, the value of $\alpha$ becomes indeterminate in the open interval $0 \leq \alpha<1$. For $\lambda_{B} \leq \lambda \leq \lambda_{\text {Max }}$, both equations $G_{w}(k, \lambda)=0$ and $\dot{\lambda}=0$ are satisfied, so the equilibrium capital-labor ratio becomes $k_{w}$. In this case, we have multiple equilibria along the segment $B B$ ', all characterized by the stationarity of the capital-labor ratio at the level $k_{w}$ and by zero profits, so the endogenous growth rate of the firm is null.

\subsection{Market Conditions and the Role of the Dis- count Rate}

The firm can also be pushed to a stationary point by the market conditions given by the ratio $w / \rho$. Given the real wage rate $w$, the ratio $k^{+}$depends, as seen, on the value of the discount rate $\rho$. If $\rho$ increases, the ratio $k^{+}$in figure 
5 decreases, so the $\dot{\lambda}=0$ curve shifts down and left. This implies the point $E$ also shifts down and left, along the $G_{w}(k, \lambda)=0$ curve, as shown by the arrowheads, until it overlaps to point $A$. At the same time, the movement to the left of the $\dot{\lambda}=0$ curve makes the point $B$ also to coincide with the point $A$.

When these three points coincide, a revenue maximizing firm does not have an endogenous growth equilibrium any more; it only has multiple stationary equilibria along the segment $B B$ ', all characterized by the stationarity of the capital-labor ratio at the level $k_{w}$. On the contrary, the equilibrium values of the shadow price of capital range from $\lambda_{A}$, which now coincides with $\lambda_{B}$, and $\lambda_{\text {Max }}$. If we indicate with $\rho_{w}$ the discount rate to which it corresponds a $\dot{\lambda}=0$ curve whose point $B$ coincides with point $A$, so as $\lambda_{B}=\lambda_{A}$, the common value of the shadow price of capital is then given by:

$$
\lambda_{A}=\frac{f\left(k_{w}\right)-k_{w} f^{\prime}\left(k_{w}\right)}{w-f\left(k_{w}\right)+k_{w} f^{\prime}\left(k_{w}\right)}=\frac{f^{\prime}\left(k_{w}\right)}{\rho_{w}-f^{\prime}\left(k_{w}\right)}=\lambda_{B}
$$

while the value of $\lambda_{\text {Max }}$, remembering equation (91), is given by:

$$
\lambda_{\text {Max }}=\frac{f^{\prime}\left(k_{w}\right)}{\rho_{w}}
$$

Because in this case $w=f\left(k_{w}\right)$, and taking account of (95), from equation (106) we get:

$$
\lambda_{A}=\lambda_{B}=\frac{f\left(k_{w}\right)-k_{w} f^{\prime}\left(k_{w}\right)}{k_{w} f^{\prime}\left(k_{w}\right)}=\frac{w}{k_{w} \rho_{w}}
$$

which can also be put in the form:

$$
M R S_{L / K}=\frac{Q_{L}}{Q_{K}}=\lambda_{A} k_{w}=\frac{w}{\rho_{w}}
$$

If we exclude the last equality, this condition corresponds to condition (56) of the static theory. It says that in a stationary equilibrium the marginal rate of substitution between labor and capital must equal the shadow value of the capital per worker. Furthermore, in a dynamic analysis, it also must equal the ratio between the real wage rate and the discount rate. So, in this case, the stationary values of $\lambda$ belong to the range:

$$
\lambda_{A}=\lambda_{B}=\frac{w}{k_{w} \rho_{w}} \leq \bar{\lambda} \leq \frac{f^{\prime}\left(k_{w}\right)}{\rho_{w}}=\lambda_{\text {Max }}
$$

If $\rho$ increases beyond $\rho_{w}$, the $\dot{\lambda}=0$ curve again shifts down and left, so point $B$ shifts under point $A$, while point $B$ ' approaches point $A$. When point $B$ ' coincides with point $A$, this remains the only stationary equilibrium point. If we indicate with $\rho_{\text {Max }}$ the corresponding discount rate, in this case we have:

$$
\lambda_{A}=\lambda_{\operatorname{Max}}=\frac{w}{k_{w} \rho_{\operatorname{Max}}}=\frac{f^{\prime}\left(k_{w}\right)}{\rho_{\operatorname{Max}}}
$$

For $\rho>\rho_{\text {Max }}$, point $B$ ' is under point $A$, which implies that $\lambda_{\text {Max }}<\lambda_{A}$, so no equilibrium exists for a revenue maximizing firm.

On the contrary, when $\rho$ decreases, always keeping a fixed real wage rate, the ratio $k^{+}$increases. When $k^{+}$ equals $k_{w}$, the dynamic equilibrium of the firm becomes a unique equilibrium of endogenous growth, corresponding to point $E$ in figure 5. Let us indicate with $\rho^{+}<\rho_{w}$ the level of the discount rate for which we have $k^{+}=k_{w}$. Then, for $\hat{r}<\rho \leq \rho^{+}$, the revenue maximizing firm has a unique dynamic equilibrium of endogenous growth in point $E$. This equilibrium stays unique until the discount rate takes another critique value given by $\hat{r}$, which corresponds to the equality $k^{+}=\hat{k}$. In fact, remembering that, according to the (17), we have $\hat{r}=f^{\prime}(\hat{k})$, from the definition of $k^{+}$ we deduce that, when $\rho=\hat{r}$, the equality $k^{+}=\hat{k}$ is satisfied.

For $\rho \leq \hat{r}$, we have $k^{+} \geq \hat{k}$, so again no equilibrium of a revenue maximizing firm exists. In this case, as we shall see later, the objective integral is no longer convergent. As $\rho \rightarrow 0$, also $f^{\prime}\left(k^{+}\right) \rightarrow 0$, so $k^{+} \rightarrow \infty$. This is why, to make the objective integral converging, the condition $\rho>\hat{r}$ must be satisfied, which implies that $\bar{r}<\hat{r}$. This also implies that the case $\bar{k}=\hat{k}$, when the equilibrium points of a revenue maximizing firm and of a profit maximizing firm should coincide, does not exist. In fact, we always have $\bar{k}<\hat{k}$.

Referring once again to figure 5, we can summarize the following cases:

- for $\rho \leq \hat{r}$, no equilibrium of the revenue maximizing firm exists;

- for $\hat{r}<\rho \leq \rho^{+}$, we have a unique equilibrium of endogenous growth corresponding to the stationary point $E$ $=(\bar{k}, \bar{\lambda})$ in figure 5

- for $\rho^{+}<\rho<\rho_{w}$, we have an endogenous growth equilibrium in point $E$ of figure 5 and multiple stationary equilibria without growth corresponding to the interval $B B^{\prime}$ in the same figure;

- for $\rho_{w} \leq \rho<\rho_{\text {Max }}$, we only have multiple stationary equilibria without growth in the interval $A B$ ', being $A$, in this case, over $B$;

- for $\rho=\rho_{\text {Max }}$, we have a unique stationary equilibrium without growth corresponding to point $A=B^{\prime}$; 
- for $\rho>\rho_{\text {Max }}$, again no equilibrium of the revenue maximizing firm exists.

\subsection{The Present Value, the Net Present Value per Unit of Capital and the Transversality Conditions}

In general, for $P=1$ and $\hat{r}<\rho \leq \rho_{\text {Max }}$, the present value $(P V)$ of future revenues of the firm is:

$$
P V=\int_{0}^{\infty} L f(k) e^{-\rho t} d t
$$

where $L=L_{0} e^{r t}$ and $L_{0}=K_{0} / k$, while $r$ is any endogenous growth rate which must be smaller than $\hat{r}$. Substituting we have:

$$
P V=\int_{0}^{\infty} L_{0} f(k) e^{-(\rho-r) t} d t
$$

It is clear that $P V$ converges only if $\rho>r$. As $\rho>\hat{r}>r$, this condition is satisfied. Dividing (113) by $K_{0}$, we obtain the present value of future revenues per unit of initial capital:

$$
\frac{P V}{K_{0}}=\int_{0}^{\infty} \frac{f(k)}{k} e^{-(\rho-r) t} d t
$$

Given $K_{0}$, when $L_{0}$ varies between infinity and zero, the capital-labor ratio $k$ varies between zero and infinity, while the instantaneous output per unit of capital $f(k) / k$, remembering (33), varies between infinity and zero, decreasing with respect to $k$. But, for $k<k_{w}$, the ratio $f(k) / k$ is not economically meaningful, because it does not respect the non bankruptcy constraint. Whereas for $k \geq k_{w}$, as in the static analysis, the ratio $f(k) / k$ is economically meaningful. It decreases with $k$ and tends asymptotically to zero as $k \rightarrow \infty$. So, its maximum value is given for $k=k_{w}$, as we can see in figure $7(c)$.

In the same way, we can define the net present value $N P V$ as follows:

$$
N P V=\int_{0}^{\infty}[L f(k)-w L] e^{-\rho t} d t
$$

where $L=L_{0} e^{r t}$ and $L_{0}=K_{0} / k$. This equation can be put in the form:

$$
N P V=\int_{0}^{\infty} L_{0}[f(k)-w] e^{-(\rho-r) t} d t
$$

which is convergent as $\rho>\hat{r}>r$. Dividing (116) by $K_{0}$, we obtain the net present value per unit of capital:

$$
\frac{N P V}{K_{0}}=\int_{0}^{\infty} \frac{f(k)-w}{k} e^{-(\rho-r) t} d t=\int_{0}^{\infty} r e^{-(\rho-r) t} d t
$$

As said, given $K_{0}$, when $L_{0}$ varies between infinity and zero, the capital-labor ratio $k$ varies between zero and infinity, while the instantaneous rate of profit varies with respect to $k$ from $-\infty$ to zero in the interval $0<k \leq k_{w}$, it becomes positive and increasing in the range $k_{w}<k<\hat{k}$, further it assumes its maximum value $\hat{r}=[f(\hat{k})-w] / \hat{k}$ for $k=\hat{k}$, and then it decreases towards zero as $k \rightarrow \infty$. As a consequence, the ratio $N P V / K_{0}$ also varies from $-\infty$ to zero in the interval $0<k \leq k_{w}$, it becomes positive and increasing in the range $k_{w}<k<\hat{k}$, further it assumes its maximum value for $k=\hat{k}$, and then it decreases towards zero as $k \rightarrow \infty$. The mapping of $r$ with respect to $k$ is also depicted in figure $7(c)$. This corresponds to the mapping of the rate of profit in the static analysis.

The condition $\rho>\hat{r}$, which is necessary for the convergence of the objective integral, is also necessary and sufficient to satisfy the transversality conditions of our optimal control problem. These conditions are:

$$
\begin{aligned}
& \lim _{t \rightarrow \infty} H_{C} e^{-\rho t}=0 \\
& \lim _{t \rightarrow \infty} \lambda e^{-\rho t}=0
\end{aligned}
$$

which must be satisfied along the optimal paths of the involved variables.

It is immediate to verify the (119), as in equilibrium we have $\lambda=\bar{\lambda}$, where $\bar{\lambda}$ is constant if the firm has an endogenous growth equilibrium in point $E$ of figure 5 , whereas it takes a value which ranges between $\lambda_{B}$ and $\lambda_{\text {Max }}$ if the firm is in a stationary equilibrium corresponding to the capital-labor ratio $k_{w}$. In both cases, as the term $e^{-\rho t} \rightarrow 0$ for $t \rightarrow \infty$, condition (119) is satisfied.

To verify condition (118), we need to write it in the extended form:

$$
\lim _{t \rightarrow \infty}[Q+\bar{\lambda} \alpha(Q-w L)] e^{-\rho t}=0
$$

If we have a stationary equilibrium, $Q$ and $L$ are constant, so equation (120) is satisfied. If, otherwise, we have an endogenous growth equilibrium, then $Q=Q_{0} e^{\overline{r t}}$ and $L=L_{0} e^{\overline{r t}}$, where $\bar{r}=[f(\bar{k})-w] / \bar{k}$ is the endogenous growth rate. Substituting these values, the condition (120) becomes:

$$
\lim _{t \rightarrow \infty}\left[Q_{0}+\bar{\lambda} \alpha\left(Q_{0}-w L_{0}\right)\right] e^{-(\rho-\bar{r}) t}=0
$$

which is satisfied because $\rho>\hat{r}>\bar{r}$.

\subsection{The Equilibrium Conditions with a Mini-} mum Acceptable Return on Capital Constraint 


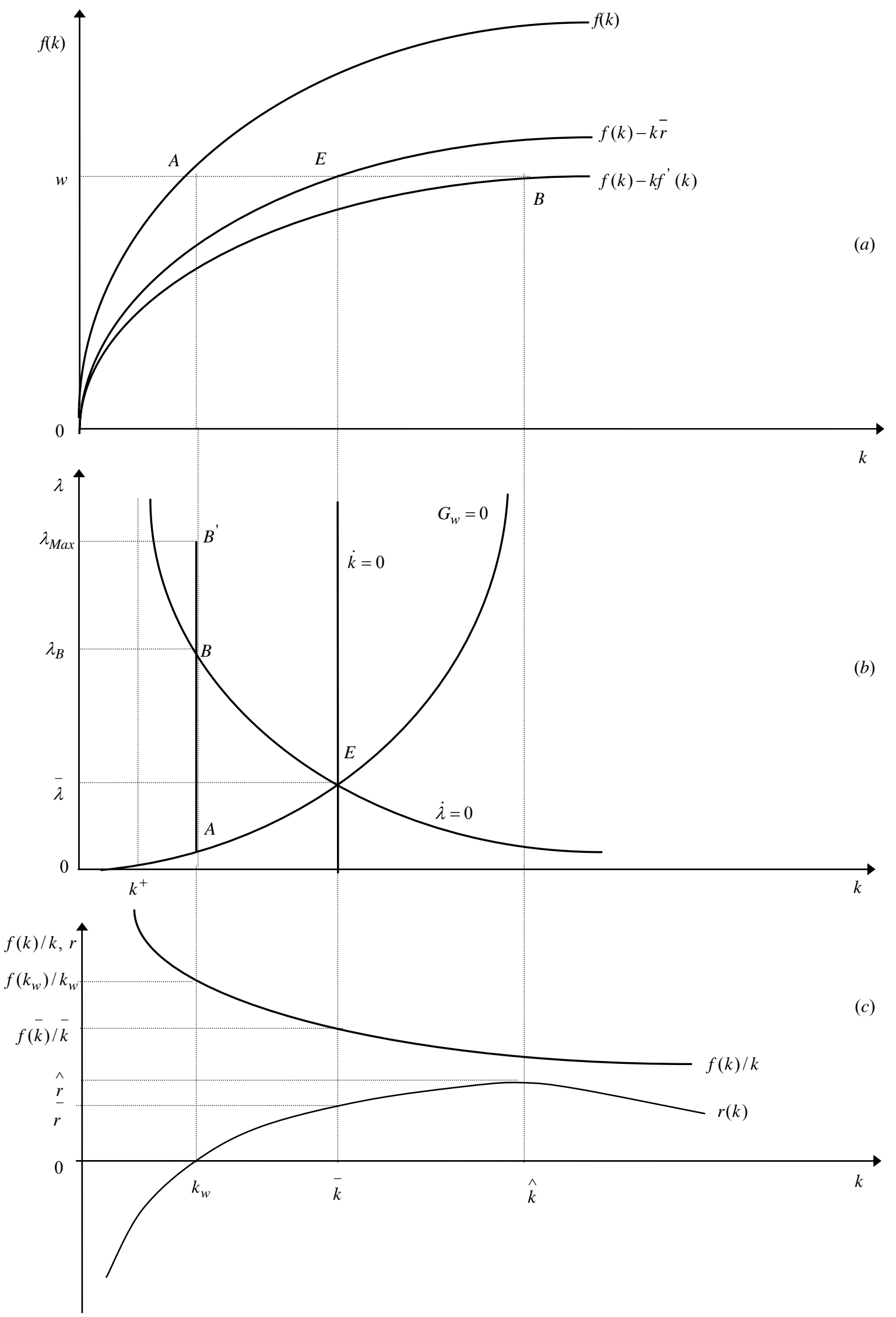

Figure 7. The endogenous growth dynamics of the revenue maximizing firm 
If the firm must respect a minimum acceptable return on capital constraint of the form:

$$
\frac{\pi}{K} \geq r_{0}, \text { for all } t \in[0, \infty]
$$

where $\pi=Q-w L$ is the instantaneous profit of the firm, then we must modify the optimal control problem to take account of this. As the constraint can also be expressed in the form:

$$
Q-w L-r_{0} K \geq 0
$$

the program of the revenue maximizing firm becomes:

Maximize $\int_{0}^{\infty} Q(K, L) e^{-\rho t} d t$

subject to

$$
\begin{aligned}
& \dot{K}=\alpha\left[Q-w L-r_{0} K\right] \\
& 0 \leq \alpha \leq 1 \\
& Q-w L-r_{0} K \geq 0
\end{aligned}
$$

and $K(0)=K_{0}, K_{\infty}$ free, $K_{0}, w, r_{0}$ given.

The current value Hamiltonian must, in this case, be extended to form a Lagrangian function in current value, which takes account of the new constraint (123). This Lagrangian is:

$$
\mathfrak{I}_{C}=Q+\lambda \alpha\left(Q-w L-r_{0} K\right)+\gamma\left(Q-w L-r_{0} K\right)
$$

where $\lambda$ and $\gamma$ are two dynamic Lagrangian multipliers expressed in current values. As $\mathfrak{I}_{c}$ is concave in $K$ and $L$, and it is linear with respect to $\alpha$, the following conditions of the maximum principle are necessary and sufficient for the solution of the program (124):

$$
\begin{aligned}
& \frac{\partial \mathfrak{I}_{C}}{\partial L}=Q_{L}+\lambda \alpha\left(Q_{L}-w\right)+\gamma\left(Q_{L}-w\right)=0 \\
& \frac{\partial \mathfrak{I}_{C}}{\partial \gamma}=Q-w L-r_{0} K \geq 0, \gamma \geq 0, \gamma\left(Q-w L-r_{0} K\right)=0 \\
& \dot{K}=\frac{\partial \mathfrak{I}_{C}}{\partial \lambda}=\alpha\left(Q-w L-r_{0} K\right) \\
& \dot{\lambda}=-\frac{\partial \mathfrak{I}_{C}}{\partial K}+\rho \lambda=-Q_{K}-\lambda \alpha\left(Q_{K}-r_{0}\right)-\gamma\left(Q_{K}-r_{0}\right)+\rho \lambda
\end{aligned}
$$

and in addition we must maximize $\mathfrak{I}_{c}$ with respect to $\alpha$. These conditions can be expressed in the following per capita form:

$$
\begin{aligned}
& G_{w}(k, \lambda)=f(k)-k f^{\prime}(k)+(\lambda \alpha+\gamma)\left[f(k)-k f^{\prime}(k)-w\right]=0 \\
& f(k)-w-r_{0} K \geq 0, \gamma \geq 0, \gamma\left[f(k)-w-r_{0} k\right]=0 \\
& \dot{k}+\frac{\dot{L}}{L} k=\alpha\left[f(k)-w-r_{0} k\right] \\
& \dot{\lambda}=-f^{\prime}(k)-(\lambda \alpha+\gamma)\left[f^{\prime}(k)-r_{0}\right]+\rho \lambda
\end{aligned}
$$

If the minimum acceptable return on capital constraint is not binding, from (131) we have $\gamma=0$. Furthermore, since $\mathfrak{I}_{C}$ is linear with respect to $\alpha$, its value is maximized for $\alpha=1$. In this case, the equations (130), (132) and (133) respectively reduce to:

$$
\begin{gathered}
\left.G_{w}(k, \lambda)=f(k)-k f^{\prime}(k)+\lambda \mid f(k)-k f^{\prime}(k)-w\right]=0 \\
\dot{k}+\frac{\dot{L}}{L} k=f(k)-w-r_{0} k>0 \\
\left.\dot{\lambda}=-f^{\prime}(k)-\lambda \mid f^{\prime}(k)-r_{0}\right]+\rho \lambda
\end{gathered}
$$

From (134) we obtain:

$$
\lambda=\frac{f(k)-k f^{\prime}(k)}{w-\left[f(k)-k f^{\prime}(k)\right]}
$$

which is the same as (77). So, all observations just referred to the $G_{w}(k, \lambda)=0$ curve also apply to (134).

As to $\dot{\lambda}=0$ curve, it now depends not only on the discount rate $\rho$, but also on the minimum return on capital constraint rate $r_{0}$. In order to stress this dependence, from now on this curve will be indicated by the symbol $\dot{\lambda}_{r}=0$. From (136), setting the stationarity condition, we obtain:

$$
\dot{\lambda}_{r}=-f^{\prime}(k)+\lambda\left[\left(\rho+r_{0}\right)-f^{\prime}(k)\right]=0
$$

from which we derive:

$$
\lambda\left(\dot{\lambda}_{r}=0\right)=\frac{f^{\prime}(k)}{\left(\rho+r_{0}\right)-f^{\prime}(k)}
$$

The only difference between this expression and (88) is that here we have $\rho+r_{0}$ in the denominator instead of only $\rho$. Hence, introducing a minimum acceptable return on capital rate $r_{0}$ is analogous to increasing the discount rate for the same amount.

Therefore, let $k^{++}$be the level of $k$ which satisfies the equation $\left(\rho+r_{0}\right)-f^{\prime}(k)=0$, so that as $k \rightarrow k^{++}$from the right we have $\lambda \rightarrow \infty$. Since $f^{\prime}(k)$ decreases with $k$, for $k>k^{++}$we have $\left(\rho+r_{0}\right)-f^{\prime}(k)>0$, which implies $\lambda>0$. Furthermore, if we differentiate equation (138), we obtain:

$$
\frac{d \lambda}{d k}=-\frac{\partial \dot{\lambda}_{r} / \partial k}{\partial \dot{\lambda}_{r} / \partial \lambda}=-\frac{-f^{\prime \prime}(k)-\lambda f^{\prime \prime}(k)}{\left(\rho+r_{0}\right)-f^{\prime}(k)}=\frac{(1+\lambda) f^{\prime \prime}(k)}{\left(\rho+r_{0}\right)-f^{\prime}(k)}<0
$$

For $k^{++}<k$, this derivative takes a negative value because the denominator is positive, whereas $f^{\prime \prime}(k)<0$. As $k \rightarrow k^{++}$from the right, $\rho+r_{0}-f^{\prime}(k) \rightarrow 0$, so $d \lambda / d k \rightarrow-\infty$. Therefore, the $\dot{\lambda}_{r}=0$ curve is asymptotic for $k \rightarrow k^{++}$from the right, it decreases when $k$ increases and it takes a null 


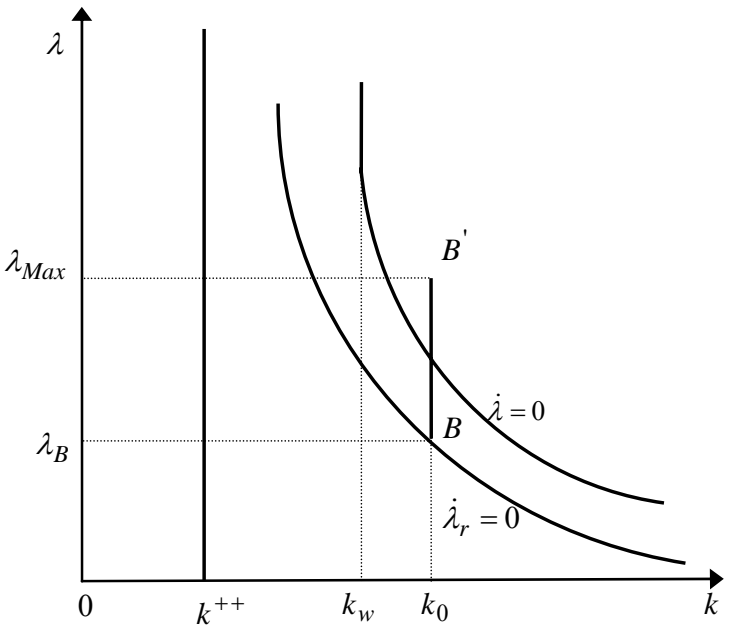

Figure 8: The mappings of $\dot{\lambda}_{r}=0$ and $\dot{\lambda}=\mathbf{0}$ curves

value as $k \rightarrow \infty$, because $\lim _{k \rightarrow \infty} f^{\prime}(k)=0$. Furthermore, as we know from its definition, the value of $k^{++}$depends on the discount rate $\rho$ and on the minimum return on capital rate $r_{0}$. Given $r_{0}$, for sufficiently high values of $\rho$, the ratio $k^{++}$is intermediate between zero and $k_{0}$, being $k_{0}$ that value of $k$ which satisfies the minimum acceptable return on capital constraint with the equality sign, that is:

$$
r_{0}=\frac{f\left(k_{0}\right)-w}{k_{0}}
$$

As it is shown in figure 8 , the $\dot{\lambda}_{r}=0$ curve is economically meaningful only for $k \geq k_{0}$, that is only for those capital-labor ratios which satisfy the minimum acceptable return on capital constraint. For $k>k_{0}$, the $\dot{\lambda}_{r}=0$ curve is defined by (139), while for $k=k_{0}$ equation (133) stays true, from which we obtain:

$$
\lambda=\frac{f^{\prime}\left(k_{0}\right)+\gamma\left[f^{\prime}\left(k_{0}\right)-r_{0}\right]}{\rho-\alpha\left[f^{\prime}\left(k_{0}\right)-r_{0}\right]}
$$

In this case, $\gamma>0$ because of equation (131), whereas $0 \leq \alpha<1$, so the maximum value of $\lambda$ is given by:

$$
\lambda_{\text {Max }}=\lim _{\alpha \rightarrow 0} \frac{f^{\prime}\left(k_{0}\right)+\gamma\left[f^{\prime}\left(k_{0}\right)-r_{0}\right]}{\rho-\alpha\left[f^{\prime}\left(k_{0}\right)-r_{0}\right]}=\frac{f^{\prime}\left(k_{0}\right)+\gamma\left[f^{\prime}\left(k_{0}\right)-r_{0}\right]}{\rho}
$$

The value of $\lambda_{B}$ can be defined as the limit of equation (139) for $k \rightarrow k_{0}$ from the right, that is:

$$
\lambda_{B}=\lim _{k \rightarrow k_{0}} \frac{f^{\prime}(k)}{\left(\rho+r_{0}\right)-f^{\prime}(k)}
$$

Overlapping the $G_{w}(k, \lambda)=0$ curve to the $\dot{\lambda}_{r}=0$ curve, we obtain figure 9 , which is similar to figure 5 , but with the difference due to the minimum acceptable return on

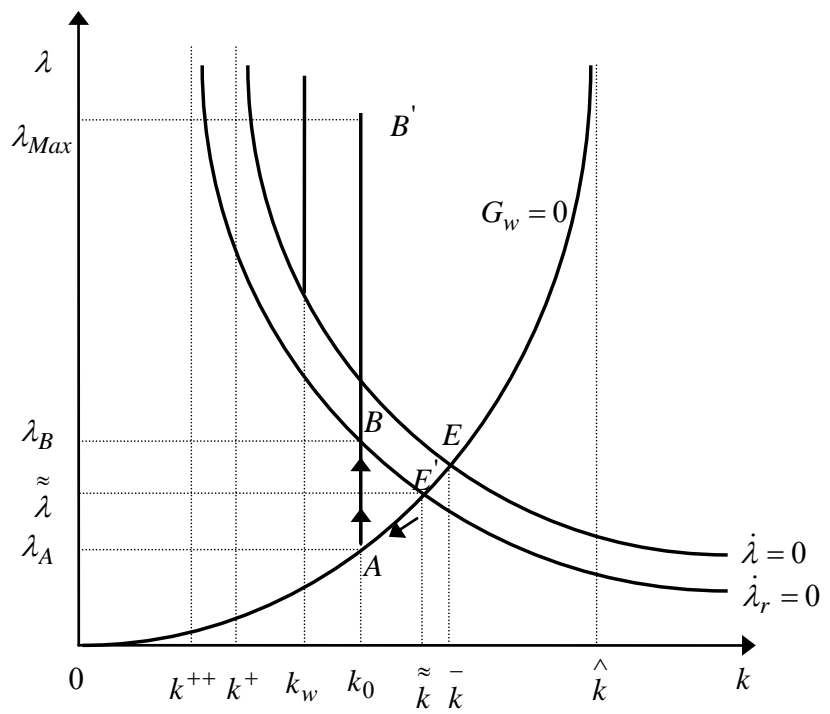

Figure 9. The dynamic equilibrium of a revenue maximizing firm (for $0<k^{++}<k_{0}$ ) with a minimum acceptable return on capital constraint

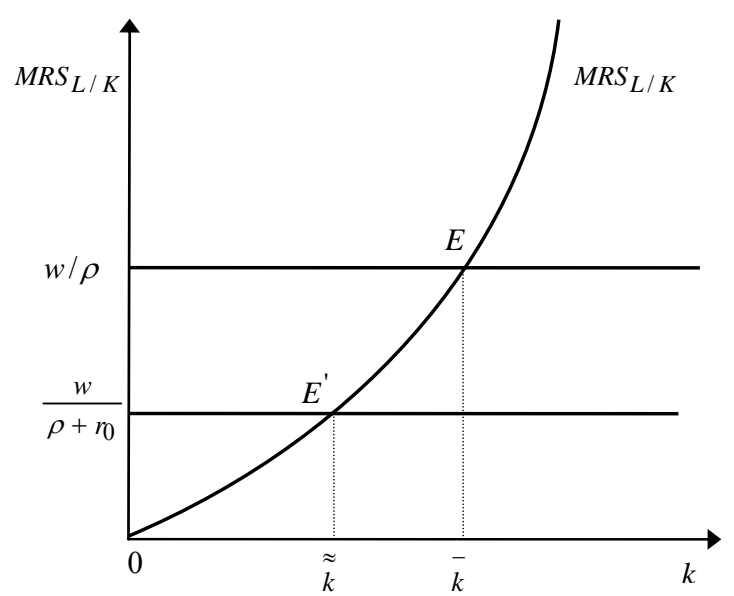

Figure 10. The endogenous growth equilibria of the revenue maximizing firm with and without a minimum acceptable return on capital constraint

capital constraint. We must point out now that the endogenous growth equilibrium is no more at point $E$, but at point $E$ ', where there is the stationarity of the capitallabor ratio at the level $\tilde{\tilde{k}}<\bar{k}$.

Taking the equations (137) and (139) together, we form a system whose solution gives the stationary value $\tilde{\tilde{k}}$, which is the equilibrium capital-labor ratio. Corresponding to this ratio, we have:

$$
M R S_{L / K}=\frac{Q_{L}}{Q_{K}}=\frac{w}{\rho+r_{0}}
$$

which is the counterpart of equation (96) in the case the firm must respect a minimum acceptable return on capital 
constraint. From (145), it is clear that $r_{0}$ exerts the same effect as $\rho$ on the equilibrium marginal rate of substitution. In figure 10 , both equilibrium conditions, given respectively by (96) and (145), are depicted.

From (135), being $\tilde{\tilde{k}}$ a stationary level of $k$, at point $E$, we have $\dot{k}=0$. This means that, remembering $\alpha=1$, from (132) we have:

$$
\dot{k}=f(\tilde{\bar{k}})-w-r_{0} \tilde{\tilde{k}}-\frac{\dot{L}}{L} \tilde{\tilde{k}}=0
$$

and the employment growth rate in $E^{\prime}$ is given by:

$$
\frac{\dot{L}}{L}=\frac{f(\tilde{\tilde{k}})-w}{\tilde{\tilde{k}}}-r_{0}=\stackrel{\approx}{r}-r_{0}
$$

where $\approx \tilde{r}=[f(\tilde{\vec{k}})-w] / \tilde{\tilde{k}}$ measures the actual return on capital rate corresponding to the equilibrium point $E^{\prime}$, that is to the capital-labor ratio $\approx$ k . Equation (147) says that in a dynamic equilibrium the employment of the firm grows at a rate equal to the difference between the real return on capital rate and the minimum acceptable return on capital rate. If we indicate with $r^{*}$ this difference, taking account of the linear homogeneity assumption on the production function, we have:

$$
r^{*}=\frac{\dot{L}}{L}=\frac{\dot{K}}{K}=\frac{\dot{Q}}{Q}=\approx \tilde{r}-r_{0}
$$

For $r_{0}=0$, the dynamic equilibrium of the firm is at point $E$ of figure 9 . In this case, $r^{*}=\tilde{r}=\bar{r}$. For $r_{0}>0$, the dynamic equilibrium of the firm is at point $E$, corresponding to a stationary capital-labor ratio equal to $\tilde{\tilde{k}}<\bar{k}$. When $r_{0}$ increases, the point $E^{\prime}$ moves along the $G_{w}(k, \lambda)=0$ curve from $E$ to $A$. For $r_{0}=\approx \tilde{r}$, when the firm gives out all profits to the stockholders, its dynamic equilibrium is at point $A$, where the capital accumulation rate and the growth rate are both zero.

We are led to the same conclusion if the minimum return on capital constraint is binding. In this case, the relations (142), (143) and (144) hold, whereas the value of $\lambda_{A}$ in figure 9 is given by:

$$
\lambda_{A}=\lim _{k \rightarrow k_{0}} \frac{f(k)-k f^{\prime}(k)}{w-\left[f(k)-k f^{\prime}(k)\right]}
$$

where the limit is calculated from equation (137) for $k \rightarrow$ $k_{0}$ from the right. Therefore, we have multiple stationary equilibria, all corresponding to the capital-labor ratio $k_{0}$, which determines an actual return on capital rate equal to $r_{0}$, that is:

$$
\tilde{r}=\frac{f\left(k_{0}\right)-w}{k_{0}}=r_{0}
$$

In this case, we have $r^{*}=\approx \tilde{r}-r_{0}=0$, and the firm is in a stationary equilibrium where all profits are given out to the stockholders to satisfy the minimum acceptable return on capital constraint. As a consequence, nothing remains to the firm to finance the accumulation of capital and its growth process.

Finally, according to the respective positions of points $A, B$ and $B$ ', we can do the same reasoning as in figure 5 . So, let $\rho_{0}$ be the value of $\rho$ for which the $\dot{\lambda}=0$ curve passes over point $A$ in figure 9 ; in order that points $A$ and $B$ coincide, and from equation (149) we have:

$$
\lambda_{A}=\lambda_{B}=\frac{f\left(k_{0}\right)-k_{0} f^{\prime}\left(k_{0}\right)}{w-\left[f\left(k_{0}\right)-k_{0} f^{\prime}\left(k_{0}\right)\right]}=\frac{f^{\prime}\left(k_{0}\right)}{\left(\rho_{0}+r_{0}\right)-f^{\prime}\left(k_{0}\right)}
$$

Substituting the value of $w-f\left(k_{0}\right)$ calculated from equation (150), we obtain:

$$
\lambda_{A}=\lambda_{B}=\frac{f\left(k_{0}\right)-k_{0} f^{\prime}\left(k_{0}\right)}{k_{0}\left[f^{\prime}\left(k_{0}\right)-r_{0}\right]}=\frac{Q_{L}}{k_{0}\left(Q_{K}-r_{0}\right)}
$$

where $Q_{L}$ and $Q_{K}$ are the marginal productivities, respectively, of labor and capital measured for $k=k_{0}$. The equation (152) can be put in the form:

$$
M R S_{L / K}\left(r_{0}\right)=\frac{Q_{L}}{Q_{K}-r_{0}}=k_{0} \lambda_{A}=k_{0} \lambda_{B}
$$

which corresponds to condition (66) just found in the static analysis. As we know, this condition says that in equilibrium the shadow value of per worker capital must equal the net marginal rate of substitution between labor and capital, where the latter, which is indicated by $M R S_{L / K}\left(r_{0}\right)$, is given by the ratio of marginal productivity of labor over the marginal productivity of capital, net of the minimum rate of return on capital $r_{0}$.

\section{Concluding Remarks}

In conclusion, we have shown that there exist three values of the equilibrium capital-labor ratio that can be found both in a static and in a dynamic analysis of the theory of the firm. They are the ratio $\hat{k}$ where the firm maximizes profits, the ratio $k_{w}$ where the firm maximizes revenue, and the ratio $k_{0}$ where the firm maximizes revenue subject to a minimum acceptable return on capital constraint, if the latter is binding.

Furthermore, we have found two values of the equilibrium capital-labor ratio that exist only in the dynamic analysis of a revenue maximizing firm. They are the ratio $\bar{k}$ where the firm is in an endogenous growth equilibrium, 
and the ratio $\tilde{\tilde{k}}$ where the firm, not only is in an endogenous growth equilibrium, but it also satisfies a minimum acceptable return on capital constraint. Obviously, when the firm is in equilibrium in $\tilde{k}$, it grows at a smaller rate than that guaranteed in $\bar{k}$, as the difference is exactly the minimum return on capital rate given out to stockholders to satisfy the constraint.

\section{REFERENCES}

[1] Anderson W. L., Profit Maximizing versus Revenue Maximizing Firms? Only time Will Tell, mimeo (http://www.mises.org/asc/2003/asc9anderson.pdf), 2003.

[2] Baumol W., Business Behavior, Value, and Growth, New York, Macmillan, 1959.

[3] Baumol W., "On the Theory of the Expansion of the Firm", American Economic Review, 52, 1962, pp.1078-87.

[4] Blinder A. S. , "International Perspective: Trading with Japan: Why the US Loses even on a Level Playing Field", Business Economics, 27, 1992, pp.25-29.

[5] Blinder A. S., "A Simple Note on the Japanese Firm", Journal of the Japanese and International Economies, 7, 1993, pp.238-55.

[6] Cheung S. N. S., "The Contractual Nature of the Firm", Journal of Law and Economics, 26, 1983, pp.1-21.

[7] Chiang A. C., Elements of Dynamic Optimization, New York, McGraw-Hill, 1992.

[8] Coase R. H., "The Nature of the Firm", Economica, 4, 1937, pp.386-485.

[9] Conner K. R., "A Historical Comparison of Resourcebased Theory of five Schools of Thought within Industrial Organization Economics: Do We Have a New Theory of the Firm?”, Journal of Management, 17, 1991, pp.121-154.

[10] Conner K. R.-Prahalad C. K., “A Resource-based Theory of the Firm: Knowledge versus Opportunism”, Organization Science, 7, 1996, pp.477-501.

[11] Cyert R. M.-Hedrick C. L., "Theory of the Firm: Past, Present, and Future; An Interpretation", Journal of Economic Literature, 10, 1972, pp.398-412.

[12] Cyert R. M.-March J. G., A Behavioral Theory of the Firm, New Jersey, Prentice Hall, 1963.

[13] Fama E., "Agency Problems and the Theory of the Firm", Journal of Political Economy, 88, 1980, pp.288-307.

[14] Foss N. J., "Theories of the Firm: Contractual and Competence Perspectives", Journal of Evolutionary Economics, 3, 1993, pp.127-44.

[15] Foss N. J., "The Theory of the Firm: The Austrians as Precursors and Critics of Contemporary Theory", Review of Austrian Economics, 7, 1994, pp.31-65.

[16] Foss N. J., "Firms, Incomplete Contracts, and Organizational Learning", Human Systems Management, 15, 1996a, pp.17-26.

[17] Foss N. J., "Knowledge-based Approaches to the Theory of the Firm: Some Critical Comments", Organization Science, 7, 1996b, pp. 470-6.
[18] Foss N. J., "Austrian Insights and the Theory of the Firm", Advances in Austrian Economics, 4, 1997, pp.175-98.

[19] Galbraith J.K., The New Industrial State, Boston, Houghton-Mifflin, 1967.

[20] Grant R. M., "Toward a Knowledge-based Theory of the Firm”, Strategic Management Journal, 17, 1996, pp.10922 .

[21] Jensen M. C., A Theory of the Firm: Governance, Residual Claims, and Organizational Forms, Boston, Harvard University Press, 2003.

[22] Jensen M. C.-Meckling W. H., "Theory of the Firm: Managerial Behavior, Agency Costs and Ownership Structure", Journal of Financial Economics, 3, 1976, pp.305-60.

[23] Kagono T.-Nonaka I.-Sakakibara K.-Okumura A., Strategic vs. Evolutionary Management: A US-Japan Comparison of Strategy and Organization, Amsterdam, Elsevier, 1985.

[24] Klein B.-Crawford R. G.-Alchian A. A., "Vertical Integration, Appropriable Rents, and the Competitive Contracting Process", Journal of Law and Economics, 21, 1978, pp.297-326.

[25] Komiya R., "Japanese Firms, Chinese Firms: Problems for Economic Reform in China", Journal of the Japanese and International Economies, 1, 1987, pp.31-61.

[26] Komiya R., Business Enterprise in Japan, Boston, The MIT Press, 1992.

[27] Larner R. J., "Ownership and Control in the 200 Largest Non-financial Corporations, 1929 and 1963", American Economic Review, 56, 1966, pp.777-87.

[28] Leland H. E., "The Dynamics of a Revenue Maximizing Firm”, International Economic Review, 13, 1972, pp.37685 .

[29] Nakamura T., The Postwar Japanese Economy, its Development and Structure, Tokyo, University of Tokyo Press, 1981.

[30] Nelson R. R.-Winter S., An Evolutionary Theory of Economic Change, Cambridge, MA, Harvard University Press, 1982.

[31] Rothbard M. N., Man, Economy, and State, Auburn (Alabama), L. von Mises Institute, 1993 ed, 1962.

[32] Tabeta N.-Wang R., "Relative Revenue-maximizing Strategy Under Cournot Duopolistic Competition: the Case of US-Japan Bilateral auto trade", SABRE Working Papers Series, n. 1996a, pp.8-96.

[33] Tabeta N.-Wang R., Who Will Be the Winner when a Profit-Maximizer Meets a Revenue-Maximizer?-The case of US-Japan Auto Trade, mimeo (http://www.ntu.edu.sg/nbs/sabre/ working_papers/1996.pdf), $1996 b$.

[34] Uekusa M.-Caves R. E., Industrial Organization in Japan, Wasinghton DC, the Brooking Institution, 1976.

[35] Van Hilton O.-Kort P.-van Loon P.J.J.M., Dynamic Policies of the Firm. An Optimal Control Approach, Berlin, Springer-Verlag, 1993.

[36] Williamson J., "Profit, Growth, and Sales Maximization", Economica, 33, 1966, pp.1-16.

[37] Williamson O. E., "Transaction-cost Economics: The 
Governance of Contractual Relations", Journal of Law and Economics, 22, 1979, pp.233-61.

[38] Williamson O. E., "The Logic of Economic Organization", in O. E. Williamson- S. G. Winter (Eds.), The Nature of the Firm - Origins, Evolution, and Development, Oxford, University Press, 1991.

[39] Winter S. G., "Economic Natural Selection and the Theory of the Firm", Yale Economic Essays, 4, 1964, pp.225-
72.

[40] Winter S. G., "On Coase, Competence, and Corporation", in O. E. Williamson- S. G. Winter (Eds.), The Nature of the Firm - Origins, Evolution, and Development, Oxford, University Press, 1991.

[41] Witt U., "Do Entrepreneurs Need Firms? A Contribution to a Missing Chapter in Austrian Economics", Review of Austrian Economics, 11, 1999, pp.99-109. 